\title{
Comparisons of Statistical Downscaling Methods for Air Temperature Over the Qilian Mountains
}

Haodong Jin ( $\nabla$ jinhd20@lzu.edu.cn )

Lanzhou University https://orcid.org/0000-0003-2643-0941

Xiaodong Li

Lanzhou University

Oliver W. Frauenfeld

Texas A\&M University

\section{Yaohua Zhao}

Lanzhou University

Cong Chen

Lanzhou University

\section{Ran Du}

Lanzhou University

Jun Du

Chinese Academy of Sciences

Xiaoqing Peng

Lanzhou University

\section{Research Article}

Keywords: Qilian Mountains, Air temperature, CMIP6, Downscaling

Posted Date: February 3rd, 2022

DOI: https://doi.org/10.21203/rs.3.rs-1264574/v1

License: (c) (i) This work is licensed under a Creative Commons Attribution 4.0 International License.

Read Full License 


\section{Comparisons of statistical downscaling methods for air temperature over the Qilian Mountains}

Haodong Jin ${ }^{1}$, Xiaodong $\mathrm{Li}^{1 *}$,Oliver W. Frauenfeld ${ }^{2}$, Yaohua Zhao ${ }^{1}$, Cong Chen $^{1}$, Ran $\mathrm{Du}^{1}$, Jun $\mathrm{Du}^{3}$, Xiaoqing Peng ${ }^{{ }^{*}}$

${ }^{1}$ Key Laboratory of Western China's Environmental Systems (Ministry of Education), College of Earth and Environmental Sciences, Lanzhou University, Lanzhou, 730000, China

${ }^{2}$ Department of Geography, Texas A\&M University, College Station, TX 77843-3147, USA

${ }^{3}$ Northwest Institute of Eco-Environment and Resources, Chinese Academy of Sciences, Lanzhou 730000, China

* Corresponding author: Xiaodong Li ( $\underline{\text { lixd16@lzu.edu.cn) }}$

Xiaoqing Peng( pengxq@1zu.edu.cn)

\section{Abstract}

Air temperature is an important indicator of climate change, as well as for understanding changes in hydrology, ecology, and other natural systems. However, meteorological stations that provide reliable temperature observations are usually sparse in areas of complex terrain, thus limiting our ability to quantify high spatial resolution temperature variability in these regions. Here, we apply three statistical downscaling methods to daily air temperature output from the sixth Coupled Model Intercomparison Project (CMIP6), validated with 22 meteorological stations over the Qilian Mountains. Based on different downscaling methods, we find RMSE and MAE are reduced as much as 59-66\%, with the ratio of RMSE and MAE to the annual average temperature of stations decreasing from $147.9 \%$ to $61.0 \%$ and $143.3 \%$ to $64.7 \%$, respectively, depending on the method. Compared to the original data, annual temperature based on the best downscaling methods differed by $-2.85 \pm 3.61^{\circ} \mathrm{C}$ during the historical $1850-2014$ period and, for the $2015-2100$ projections, by $2.13 \pm 3.30^{\circ} \mathrm{C}$ for SSP1-2.6, $-2.13 \pm 3.29^{\circ} \mathrm{C}$ for SSP2-4.5, $-2.11 \pm 3.24^{\circ} \mathrm{C}$ for SSP3-7.0, and $-2.12 \pm 3.23^{\circ} \mathrm{C}$ for SSP5-8.5. The downscaled annual air temperatures show a warming trend ranging $0.15-0.22^{\circ} \mathrm{C} / 10 \mathrm{yr}$ for the historical experiment, $0.08^{\circ} \mathrm{C}-0.14^{\circ} \mathrm{C} / 10 \mathrm{yr}$ for SSP1-2.6, $0.24-0.35^{\circ} \mathrm{C} / 10 \mathrm{yr}$ for SSP2-4.5, $0.43-0.63^{\circ} \mathrm{C} / 10 \mathrm{yr}$ for SSP3-7.0, and $0.52-0.76^{\circ} \mathrm{C} / 10 \mathrm{yr}$ for SSP5-8.5 in the Qilian Mountain. These 
results indicate that the accuracy of the downscaled temperatures is improved compared to the original data. However, we also find that, compared with the downscaled data, the original projections have been overestimated.

Keywords: Qilian Mountains; Air temperature; CMIP6; Downscaling

\section{Introduction}

Near-surface air temperature is a vital indicator of climate change that exerts a strong influence on many environmental processes such as the water and energy cycles (Bolstad, Swift, Collins, \& Régnière, 1998; Mao, Tang, Wang, Zhou, \& Wang, 2008; Prihodko \& Goward, 1997; Prince, Goetz, Dubayah, Czajkowski, \& Thawley, 1998). Also, temperature significantly impacts the turbulent exchange between the surface and atmosphere, plant growth, and many other interactions between the Earth's surface and the atmosphere (Dodson \& Marks, 1997; Maurer, Wood, Adam, Lettenmaier, \& Nijssen, 2002; Minder, Mote, \& Lundquist, 2010; Mooney, Mulligan, \& Fealy, 2011; Mote, 2006). Hence, near-surface air temperatures from historical and projected time series are vital for quantifying climate change and analyzing various influences on the natural environment. In addition, it is an important forcing variable for model applications such as for land surface models.

Meteorological stations are generally considered as the best source of observed near-surface temperatures. However, there are very few meteorological stations in areas of complex terrain, especially in mountainous regions with high altitudes ( $\mathrm{Lu}$ Gao, Schulz, \& Bernhardt, 2014) due to their inaccessibility and cost of maintenance (Kunkel, 1989; Rolland, 2003). Therefore, near-surface temperature is usually estimated from meteorological stations by using interpolation methods such as nearest neighbor, inverse distance weighting, and many others. The accuracy of these methods is mostly dependent on station density (Ishida \& Kawashima, 1993; VicenteSerrano, Saz-Sánchez, \& Cuadrat, 2003). At present, there are two common downscaling methods: dynamical and statistical. Dynamical downscaling uses regional climate models to project higher-resolution climate change for historical or future scenarios (Coppola \& Giorgi, 2010; X. Gao, Shi, \& Giorgi, 2011). Its advantages are that it is physically-based, with varying resolution, and that it can be 
applied to any area without the need for observational data (Hay \& Clark, 2003; Maraun et al., 2010). But a substantial disadvantage is the large computational cost (Hagemann et al., 2004; Kiefer \& Zhong, 2015). Statistical downscaling is based on observations and coarse-resolution fields from global climate models, where the statistical relationship between them is used to obtain higher-resolution projections (Yang, Li, Wang, Xu, \& Yu, 2012). Statistical downscaling is reasonably effective, but also has several limitations, particularly in complex terrain, which impact its applicability (Chu, Xia, Xu, \& Singh, 2010; Souvignet, Gaese, Ribbe, Kretschmer, \& Oyarzun, 2010).

The sixth phase of the Coupled Model Intercomparison Project (CMIP6) is aimed at addressing new scientific questions regarding climate change, and providing data support for the scientific goals established by the World Climate Research Programme Grand Challenges program (Eyring et al., 2016). However, the uncertainties of CMIP6 outputs, with their still relatively coarse resolution, cannot be ignored (Collins et al., 2017). For example, atmospheric features in complex terrain such as temperature inversions in valleys, are not well captured. However, environmental models need data with higher resolution air temperature forcings to correctly simulate these, and other processes. Thus, it is necessary to downscale and correct CMIP6 temperature fields for further research.

The Qilian Mountains serve an important ecological function in northwestern China and also represent an important water source for the Yellow River basin (Figure 1). The topography of the area is mainly composed of sediments, fractured rock, and valleys between mountains (Li et al., 2017; X. Wang et al., 2013). Because of the Qilian Mountains' geographic location and complex terrain, different datasets and downscaling methods are likely to result in biases and uncertainties. In this study, we therefore assess four approaches for downscaling air temperature from CMIP6 outputs for the Qilian Mountains. 


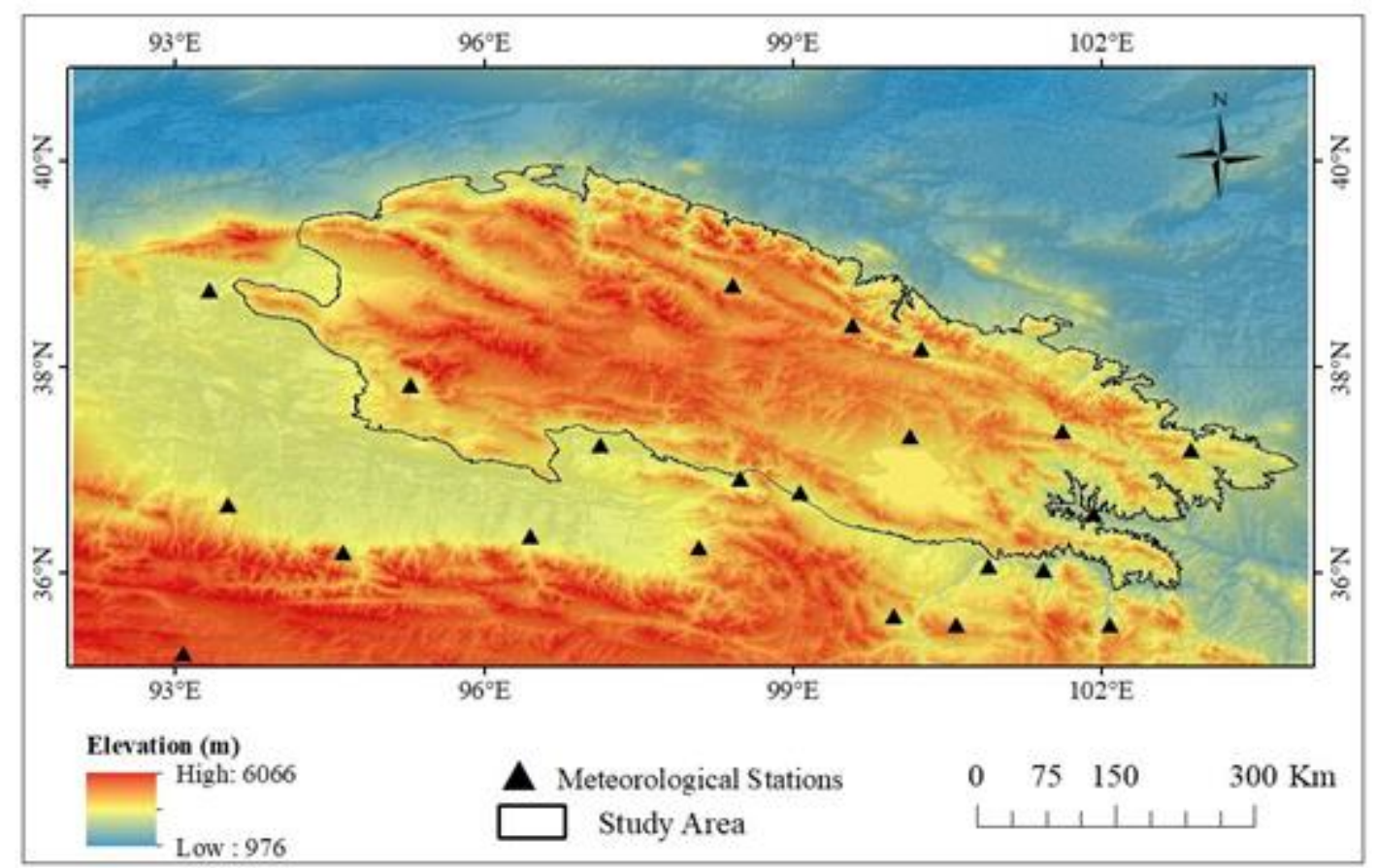

Figure 1 The terrain of the Qilian Mountains and the location of the 22 meteorological stations (triangles) in the study area

\section{Data and Methods}

\subsection{CMIP6 outputs}

Daily 2-m temperatures, surface elevation, and air temperature data at the 1000 , 850, 700, and $500 \mathrm{hPa}$ pressure levels from CMIP6 outputs were used in this study, downloaded from https://esgf-node.llnl.gov/projects/esgf-1lnl/. The data in each CMIP6 model is composed of the historical 1850-2014 period and projections for 2015-2100. Simulations for the future period are based on several shared socioeconomic pathways (SSPs). Based on data availability, we selected 5 models (Table 1) and five scenarios-historical, SSP1-2.6, SSP2-4.5, SSP3-7.0, and SSP58.5 - and calculated the model-mean temperature for each model. Additional detail for each model is shown in Table 1.

Table 1. CMIP6 models used in this study.

\begin{tabular}{ccc}
\hline Model & Spatial Resolution $($ lat $\times$ lon $)$ & Country \\
\hline AWI-ESM-1-1-LR & $96 \times 192$ & Germany \\
AWI-CM-1-1-MR & $192 \times 384$ & Germany \\
BCC-CSM2-MR & $160 \times 320$ & China \\
\hline
\end{tabular}




\begin{tabular}{ccc}
\hline NorESM2-MM & $192 \times 288$ & Norway \\
TaiESM1 & $192 \times 288$ & China \\
\hline
\end{tabular}

\subsection{Observations}

Daily air temperature data from 22 meteorological stations located across the Qilian Mountains were obtained from the China Meteorological Data Sharing Service System of the National Meteorological Information Center (http://cdc.nmic.cn/home.do) (Figure 1 and Table 2). The quality control and assurance of these observed data is provided by the National Meteorological Information Center of China. Observations ranging from 1981 to 2014 are used here, to verify the downscaled results.

Table 2. List of the meteorological stations with their location and elevation.

\begin{tabular}{cccc}
\hline ID & Latitude $\left({ }^{\circ} \mathrm{N}\right)$ & Longitude $\left({ }^{\circ} \mathrm{E}\right)$ & Elevation $(\mathrm{m})$ \\
\hline 52602 & 38.75 & 93.33 & 2770 \\
52633 & 38.80 & 98.42 & 3367 \\
52645 & 38.42 & 99.58 & 3180 \\
52657 & 38.18 & 100.25 & 2787 \\
52707 & 36.67 & 93.52 & 2771 \\
52713 & 37.83 & 95.28 & 3000 \\
52737 & 37.25 & 97.13 & 2762 \\
52754 & 37.33 & 100.13 & 3302 \\
52765 & 37.38 & 101.62 & 2708 \\
52787 & 37.20 & 102.87 & 3045 \\
52818 & 36.20 & 94.63 & 2806 \\
52825 & 36.37 & 96.45 & 2790 \\
52833 & 36.92 & 98.48 & 2950 \\
52836 & 36.25 & 98.08 & 3400 \\
52842 & 36.78 & 99.07 & 3088 \\
52856 & 36.07 & 100.90 & 3500 \\
52866 & 36.58 & 101.92 & 2231 \\
52868 & 36.03 & 101.43 & 2237 \\
52908 & 35.22 & 93.08 & 4612 \\
52943 & 35.58 & 99.98 & 3323 \\
52955 & 35.50 & 100.58 & 3000 \\
52974 & 35.50 & 102.08 & 2488 \\
\hline
\end{tabular}

\subsection{Methods}

Four downscaling methods were used, and methods 2-4 are assessed relative to method 1. According to Tobler (1970)'s first law of geography, “everything is related to everything else, but near things are more related than distant things." Therefore, method 1 applies bilinear interpolation to resample the spatial resolution of CMIP6 
temperature data to $1 \mathrm{~km}$ (Rong et al., 2011). Previous studies suggested that air temperature varies by elevation, especially in high mountains (L Gao, Bernhardt, \& Schulz, 2012; Lu Gao, Hao, \& Chen, 2014). Therefore, method 2 is mainly based on elevation, according to equation (1) (Lu Gao et al., 2018) where $T$ is the downscaled temperature, $T_{2 m}$ is the CMIP6 2-m temperature, and $\Gamma$ is the lapse rate with a decrease of air temperature with geopotential height at the corresponding pressure levels. We use $\Gamma_{850-1000}($ elevation $\leq 1500 \mathrm{~m}), \Gamma_{700-850}(1500<$ elevation $<3000$ $\mathrm{m})$, and $\Gamma_{500-700}($ elevation $\geq 3000 \mathrm{~m}$ ), with $\Delta \mathrm{h}$ being the altitude difference between the $1 \mathrm{~km}$ digital elevation model (DEM from GTOPO30) and the surface elevation from each CMIP6 model.

$$
T=T_{2 m}+\Gamma * \Delta \mathrm{h}
$$

Computing near-surface air temperature directly from different pressure levels is another potential technique (Fiddes \& Gruber, 2014). Method 3 thus employs linear interpolation from air temperatures at different geopotential heights according to equation (2), where $T_{a}$ is the standard temperature based on $T_{1000}$ (elevation $\leq 1500$ $\mathrm{m}), T_{850}(1500<$ elevation $<3000 \mathrm{~m})$, and $T_{700}$ (elevation $\left.\geq 3000 \mathrm{~m}\right)$. The lapse rate $\Gamma$ indicates a decrease of air temperature with geopotential height at the corresponding pressure levels, and $\Delta \mathrm{h}$ is the difference between the DEM and CMIP6 grid geopotential height at the corresponding pressure levels.

$$
T=T_{a}+\Gamma * \Delta \mathrm{h}
$$

In complex terrain, the surface air temperature in low elevations (e.g., valleys) is mainly influenced by the near-surface, while in high elevation areas (e.g., mountains) it is primarily controlled by the upper-air temperatures (Tabony, 1985). This suggests that elevation can be used as a substitute index of the influence of the surface on the atmosphere. Therefore method 4 combines the above two approaches and is based on a hypsometric position obtained by calculating the ratio from the number of grid cells with elevations higher than this location to the total number of grid cells in the area of interest. The values range from 0 to 1 , representing the lowest valleys (0) to the highest peaks (1) (Cao et al., 2019). The results of method 2 are used to derive temperature for areas with a hypsometric position greater than 0.3 , which we consider 
to correspond to areas dominated by surface effects (Cao, Gruber, \& Zhang, 2017). The results of method 3 are used to derive temperature for areas with hypsometric positions smaller than 0.1, considered to correspond to areas dominated by the upper-air temperature, such as mountain tops. A combination was used for the other areas. Cao et al. (2019) found that this method is very effective for downscaling temperatures in mountainous areas. The temperature can be calculated as:

$$
T=\alpha * T_{2}+(1-\alpha) * T_{3}
$$

where $T_{2}$ is the temperature derived from method 2 and $T_{3}$ is from method $3 ; \alpha$ is the fractional contribution of $T_{2}$ to $T$, and can be written as:

$$
\alpha=\left\{\begin{array}{rc}
0, & H \leq H_{u} \\
\frac{H-H_{u}}{H_{l}-H_{u}} & H_{u}<H<H_{l} \\
1, & H \geq H_{l}
\end{array}\right.
$$

where $H$ is the hypsometric position estimated from GTOPO30, $H_{u}$ is the upper boundary of the hypsometric position, and $H_{l}$ is the lower boundary. For $H_{l}$ and $H_{u}$ we use 0.3 and 0.1 , respectively, in this study.

\subsection{Verification}

To evaluate the downscaled temperatures, two statistical accuracy measures were applied. The root-mean-square error (RMSE) and mean absolute error (MAE) were used for assessing the bias between the downscaled data and observations:

(1)

$$
\begin{gathered}
\mathrm{RMSE}=\sqrt{\frac{\sum_{N}\left(x_{i}-\hat{x}_{i}\right)^{2}}{N-1}} \\
M A E=\frac{1}{N} \sum N\left|x_{i}-\overline{\hat{x}}_{l}\right|
\end{gathered}
$$

where $\mathrm{N}$ is the total number of observations, $i$ is the sequence of observation stations, $x_{i}$ are observed temperatures, and $\overline{\hat{x}}_{l}$ are the downscaled temperatures. For trends and where differences in means are compared, t-tests are used to determine statistical significance at the $95 \%$ level.

\section{Results}

\subsection{Evaluation of downscaling methods}

Comparing statistical downscaling methods 2-4 relative to the original data (method 1), annually averaged MAEs and RMSEs are $1.30^{\circ} \mathrm{C}$ and $1.38^{\circ} \mathrm{C}$ for method $2,1.39^{\circ} \mathrm{C}$ 
and $1.47^{\circ} \mathrm{C}$ for method 3 , and $1.23^{\circ} \mathrm{C}$ and $1.32^{\circ} \mathrm{C}$ for method 4 . The ratios of RMSE and MAE to the annual average temperatures at stations are $147.9 \%$ and $143.3 \%$ for method $1,62.1 \%$ to $55.8 \%$ for method $2,88.2 \%$ and $82.1 \%$ for method 3 , and $61.0 \%$ and $54.7 \%$ for method 4 , The overall performance of the downscaling methods for all stations thus shows that method 4 performs the best. Annual RMSE and MAE for method 4 range from $0.43^{\circ} \mathrm{C}$ to $4.29^{\circ} \mathrm{C}$ and $0.36^{\circ} \mathrm{C}$ to $4.26^{\circ} \mathrm{C}$, respectively (Figure 2), outperforming the other methods with a $63 \%$ reduction in RMSE and a $65 \%$ reduction in MAE with respect to the RMSE and MAE of the CMIP6 data based on the basic bilinear interpolation (method 1). In terms of a monthly evaluation, the worst and best results occurred in February and October, respectively. Taking method 4 as an example, the monthly average RMSE and MAE of method 4 are $3.03^{\circ} \mathrm{C}$ and $2.66^{\circ} \mathrm{C}$ in February, and $1.49^{\circ} \mathrm{C}$ and $1.27^{\circ} \mathrm{C}$ in October (Figure 2). Finally, a daily evaluation indicates the maximum and minimum errors occur in winter and summer, and method

1914 still performs the best. The daily RMSE and MAE for method 4 range from $2.28^{\circ} \mathrm{C}$ 192 to $5.44^{\circ} \mathrm{C}$, and $1.85^{\circ} \mathrm{C}$ to $4.42^{\circ} \mathrm{C}$ (Figure 3 ). 
(a)

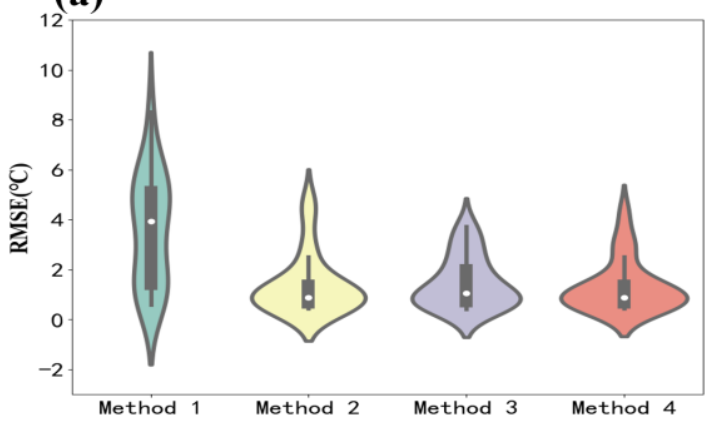

(c)

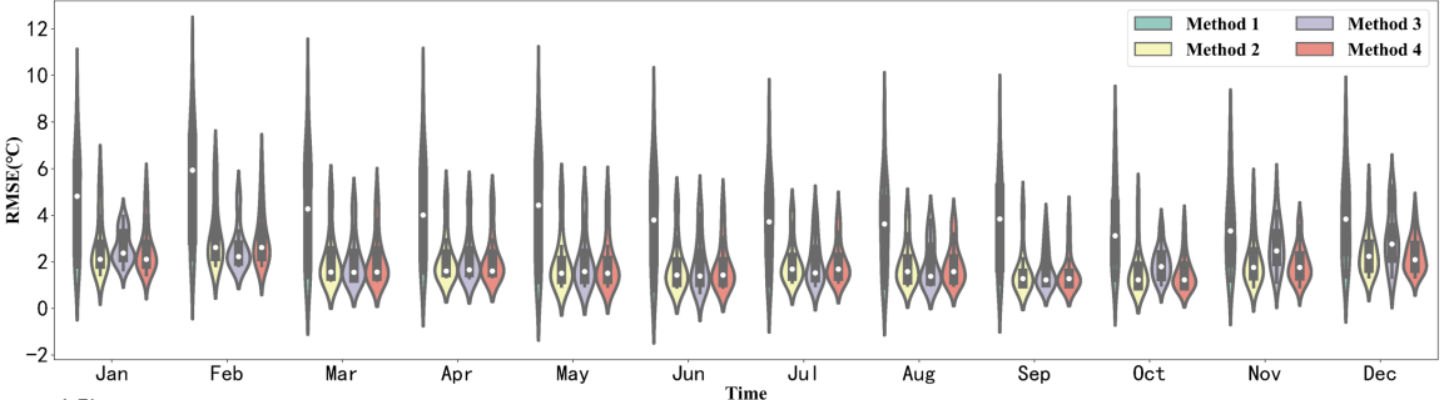

(d)

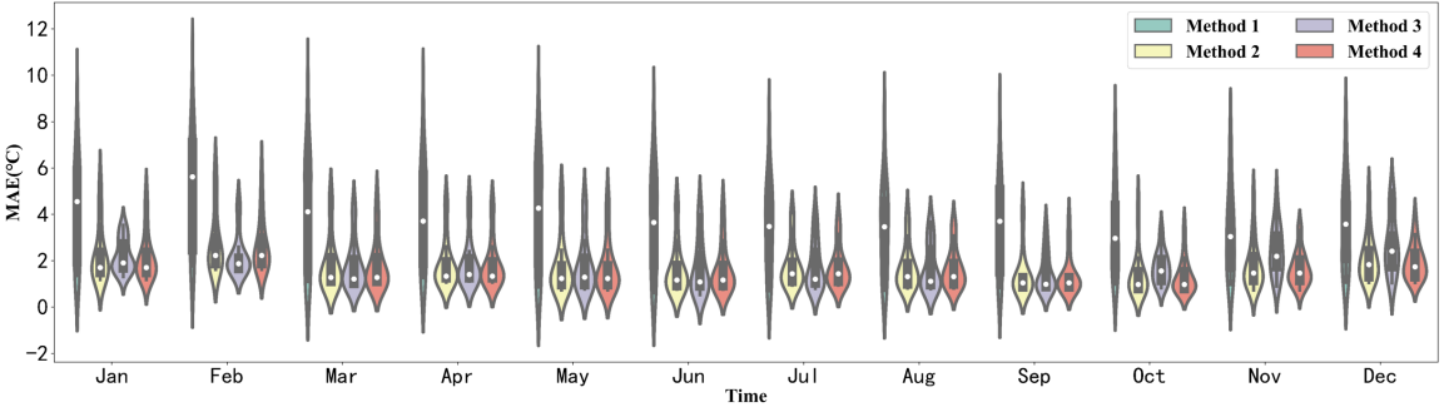

(b)

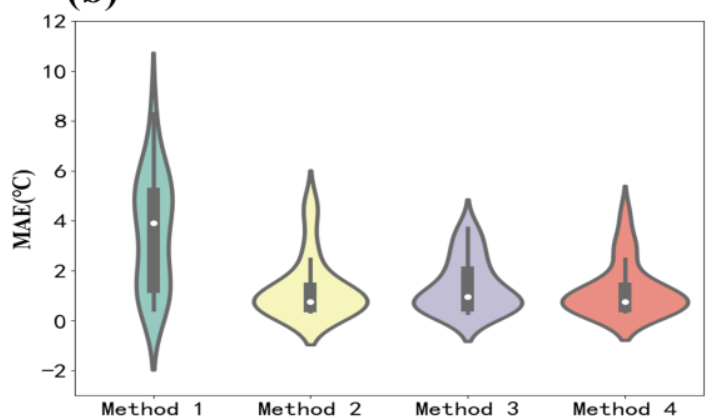

Figure 2 Violin plots of (a) annual RMSE, (b) annual MAE, (c) monthly RMSE, and (d) monthly MAE for observations (1981-2014). The width represents the frequency of occurrence, the thick black bar in the middle represents the quartile range, the thin black line extending from it represents the $95 \%$ confidence interval, and the white dot is the median

(a)

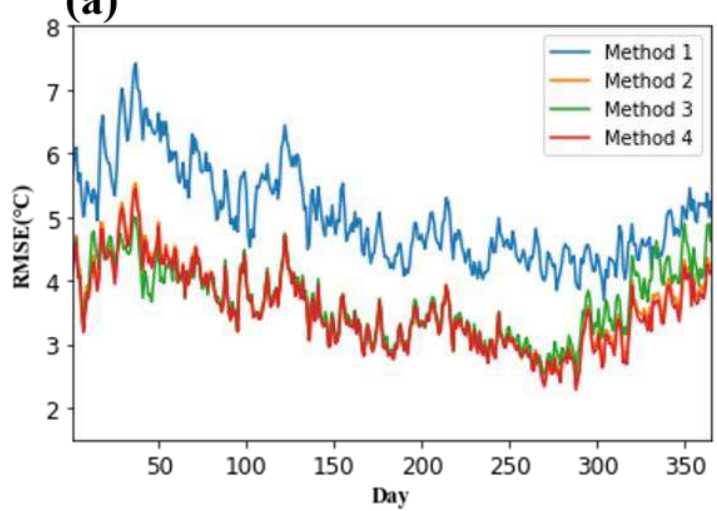

(b)

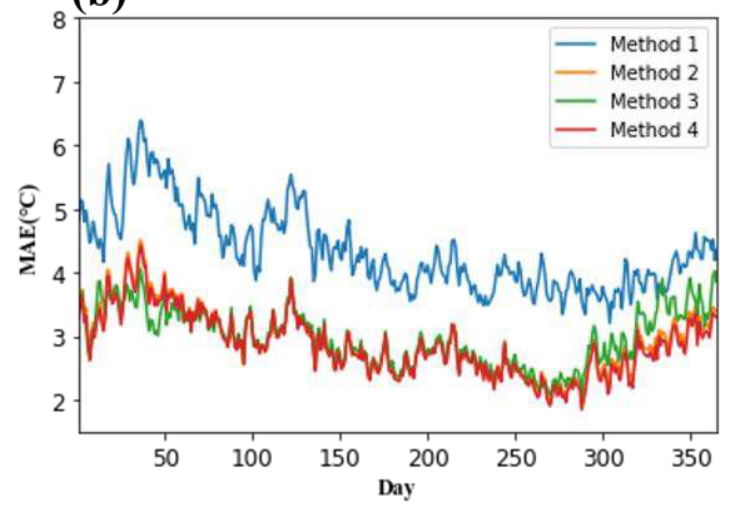

Figure 3 Daily (a) RMSE and (b) MAE for observations

\subsection{Historical air temperature climatology and trends}


The Qilian Mountains-wide temperature climatology and warming trends are surveyed based on the annual mean temperature from CMIP6 and downscaled temperature data. The spatial pattern of annual temperature in the recent 30 year climatology (1981-2010) for the four methods over the Qilian Mountains is similar, showing high elevation regions with a relatively low temperature (Figure 4). The 30year mean annual temperatures are $0.30 \pm 1.44^{\circ} \mathrm{C},-2.62 \pm 3.82^{\circ} \mathrm{C},-1.94 \pm 3.98^{\circ} \mathrm{C}$, and $-2.56 \pm 3.83^{\circ} \mathrm{C}$ for methods $1-4$, respectively. The differences in annual temperature patterns between methods $2-4$ and the original data (method 1 ) ranged from $-18.81^{\circ} \mathrm{C}$ to $8.46^{\circ} \mathrm{C}$ for method 2 , from $-18.03^{\circ} \mathrm{C}$ to $9.72^{\circ} \mathrm{C}$ for method 3 , and from $-18.81^{\circ} \mathrm{C}$ to $9.04^{\circ} \mathrm{C}$ for method 4 (Figure 5). The original data overestimates temperatures over most parts of the Qilian Mountains, especially the high-elevation regions. The average difference across the area is $-2.92 \pm 3.61^{\circ} \mathrm{C},-2.24 \pm 3.71{ }^{\circ} \mathrm{C}$, and $-2.85 \pm 3.61^{\circ} \mathrm{C}$ for methods $2-4$, respectively.

The annual mean temperature trends in the historical period (1950-2014) show warming for all the regions, downscaled via the four methods (Figure 6). The mean warming trends for the Qilian Mountains in the historical period based on the four methods, respectively, range from $0.16^{\circ} \mathrm{C} / 10 \mathrm{yr}$ to $0.21^{\circ} \mathrm{C} / 10 \mathrm{yr}, 0.15^{\circ} \mathrm{C} / 10 \mathrm{yr}$ to $0.22^{\circ} \mathrm{C} / 10 \mathrm{yr}, 0.15^{\circ} \mathrm{C} / 10 \mathrm{yr}$ to $0.20^{\circ} \mathrm{C} / 10 \mathrm{yr}$, and $0.15^{\circ} \mathrm{C} / 10 \mathrm{yr}$ to $0.22^{\circ} \mathrm{C} / 10 \mathrm{yr}$ for method 4. The area-averaged mean annual air temperature trends are $0.183 \pm 0.016^{\circ} \mathrm{C} / 10 \mathrm{yr}, \quad 0.184 \pm 0.016^{\circ} \mathrm{C} / 10 \mathrm{yr}, \quad 0.181 \pm 0.010^{\circ} \mathrm{C} / 10 \mathrm{yr}, \quad$ and $0.183 \pm 0.016^{\circ} \mathrm{C} / 10 \mathrm{yr}$ for methods $1-4$. Generally, a higher warming trend occurs in high elevation regions. 

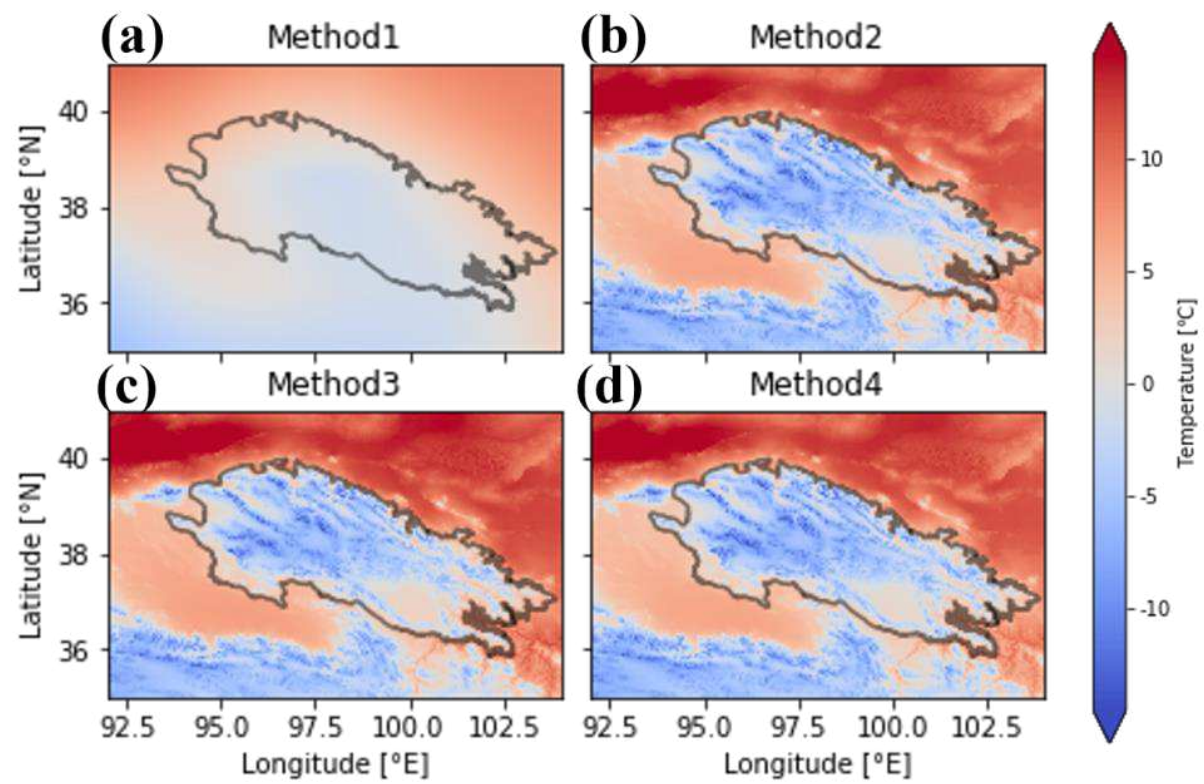

Figure 4 The spatial pattern of annual air temperature for methods $1-4$ (a-d) in the

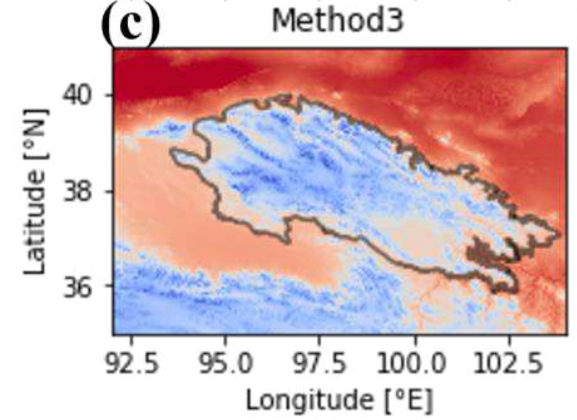

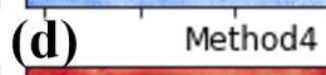

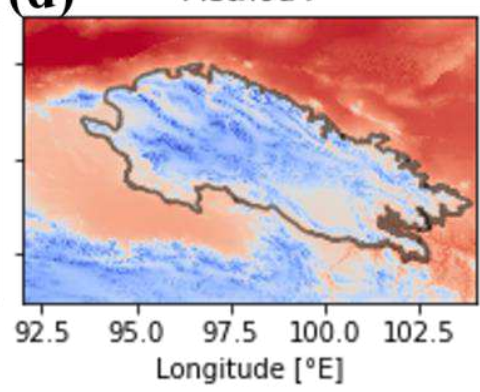

\section{它}

historical period(1981-2010)

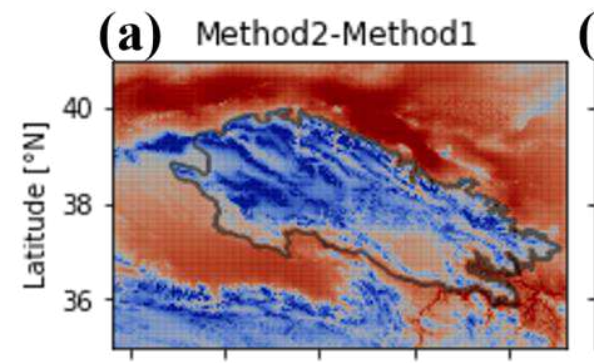

(b) Method3-Method1
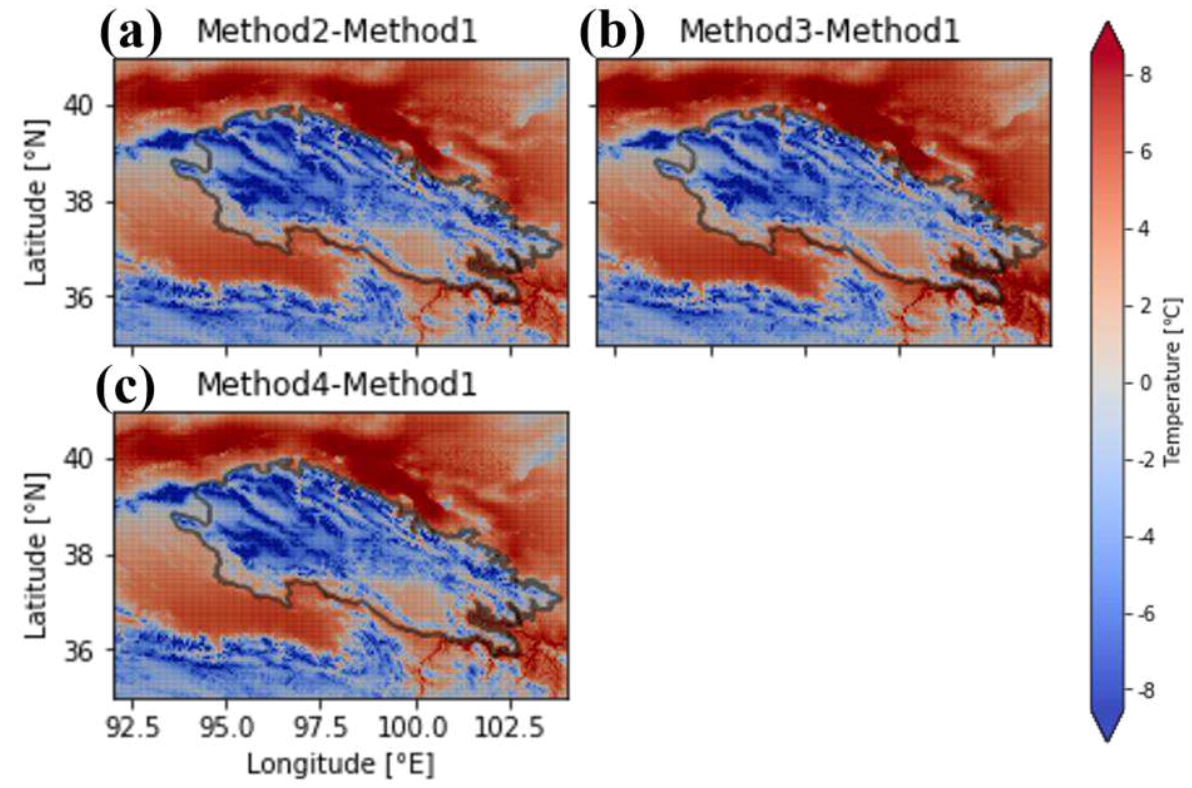

228 Figure 5 Average temperature difference in 1981-2010 between methods 2-4 (a-c) relative to the original data (method 1). Statistically significant differences are indicated by black dots. 

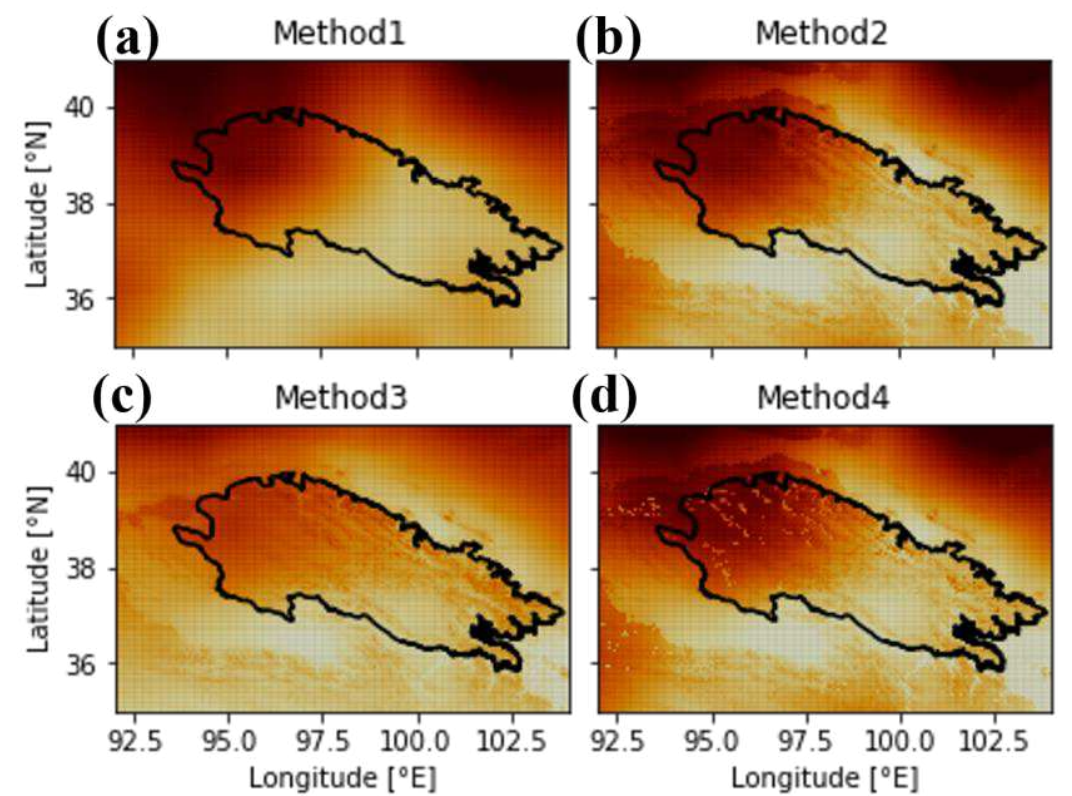

(d)

Method4

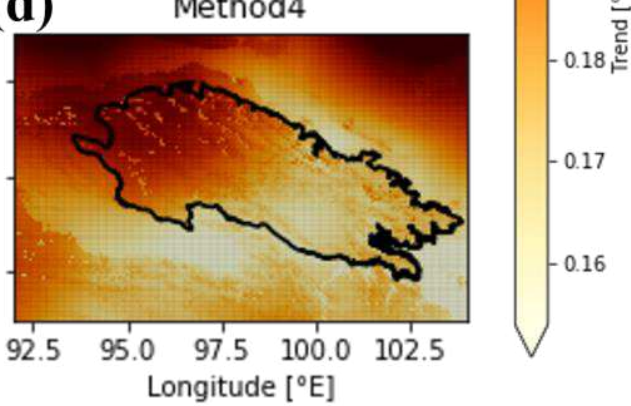

Figure 6 Temperature trends for methods 1-4 (a-d) in the historical period (19502014). The regions with statistically significant trends are marked with black dots.

\subsection{Future air temperature changes}

We calculate the spatial pattern of annual temperature for 2071-2100 based on the four downscaling methods and for four scenarios (SSP1-2.6, SSP2-4.5, SSP3-7.0, and SSP5-8.5). Taking method 4 as an example (methods 1-3 are shown in Figures S1-8), the 2071-2100 mean annual temperatures over the Qilian Mountains range from $-14.55^{\circ} \mathrm{C}$ to $10.80^{\circ} \mathrm{C}$ for $\operatorname{SSP} 1-2.6,-13.20^{\circ} \mathrm{C}$ to $11.84^{\circ} \mathrm{C}$ for $\mathrm{SSP} 2-4.5$, $-11.61^{\circ} \mathrm{C}$ to $12.99^{\circ} \mathrm{C}$ for SSP3-7.0, and $-10.66^{\circ} \mathrm{C}$ to $13.75^{\circ} \mathrm{C}$ for SSP5-8.5 (Figure 7). The 2071-2100 difference in annual temperatures between method 4 and the original data (method 1) ranges from $-17.22^{\circ} \mathrm{C}$ to $9.14^{\circ} \mathrm{C}$ for $\mathrm{SSP} 1-2.6,-17.17^{\circ} \mathrm{C}$ to $9.02^{\circ} \mathrm{C}$ for SSP2-4.5, $-16.99^{\circ} \mathrm{C}$ to $8.84^{\circ} \mathrm{C}$ for SSP3-7.0, and $-16.97^{\circ} \mathrm{C}$ to $8.68^{\circ} \mathrm{C}$ for SSP58.5 (Figure 8 ). These differences also indicate that the original values overestimate temperature in most areas. The average differences, comparing method 4 and the original data in the future across the area, are $-2.13 \pm 3.30^{\circ} \mathrm{C}$ for SSP1-2.6, $-2.13 \pm 3.29^{\circ} \mathrm{C}$ for SSP2 $-4.5,-2.11 \pm 3.24^{\circ} \mathrm{C}$ for SSP3-7.0, and $-2.12 \pm 3.23^{\circ} \mathrm{C}$ for SSP5-8.5.

The 2015-2100 annual mean temperature trend shows warming for all four scenarios over the Qilian Mountains, ranging $0.08-0.14^{\circ} \mathrm{C} / 10 \mathrm{yr}$ for SSP1-2.6, $0.24-$ 

for SSP5-8.5 (Figure 9).

According to the annual mean temperatures based on the four methods from the historical to the future periods (Figure 10), the three statistical downscaling methods all underestimate the temperature in the area compared to the original temperatures. The improved accuracy of the downscaled data based on these three methods suggests the original data overestimate temperatures in the high-elevation regions.
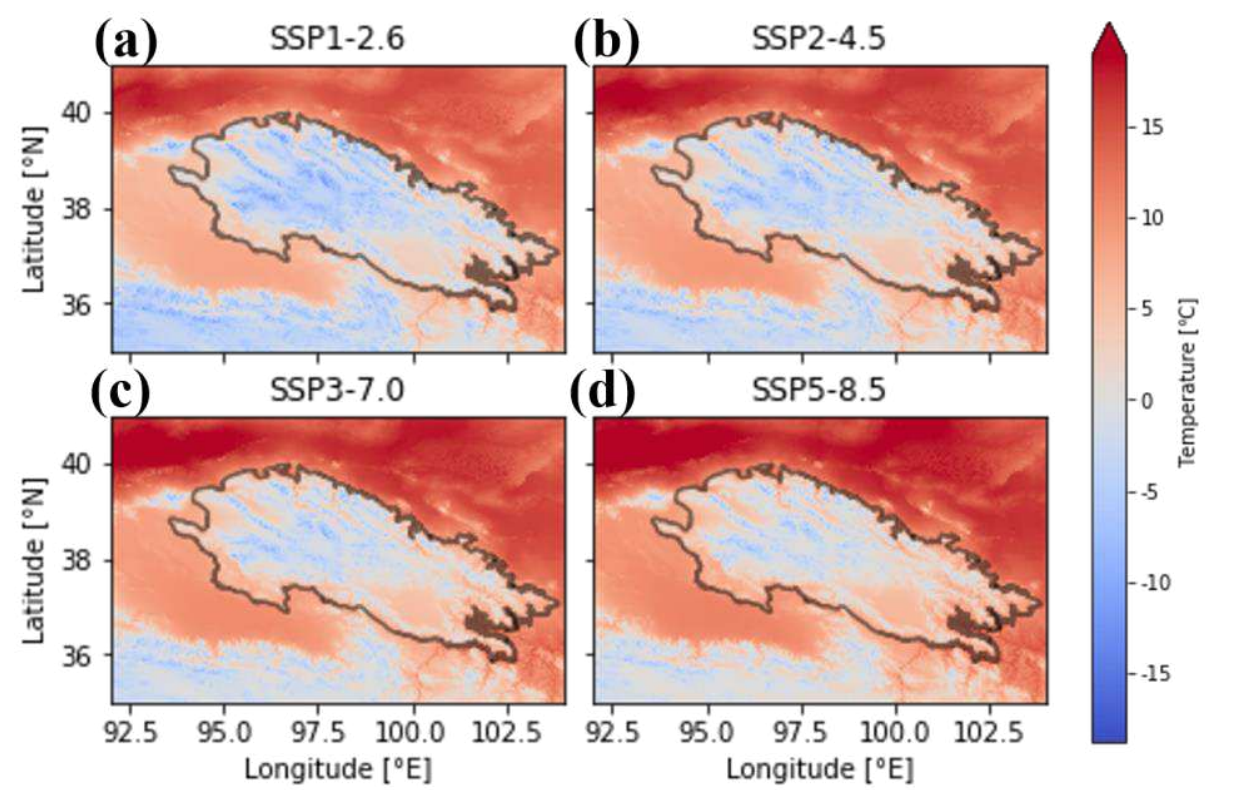

260

Figure 7 The spatial pattern of annual air temperatures for the four emission scenarios 261

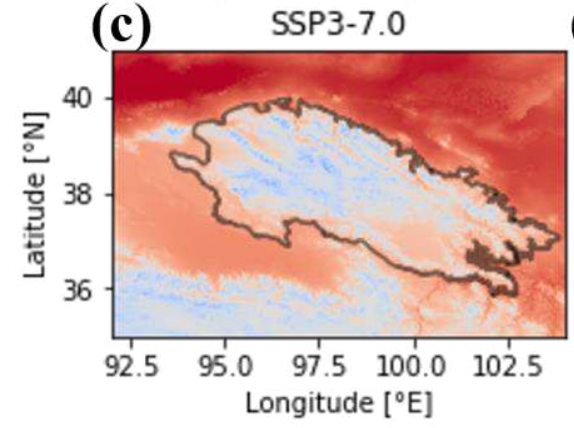

(d)

SSP5-8.5

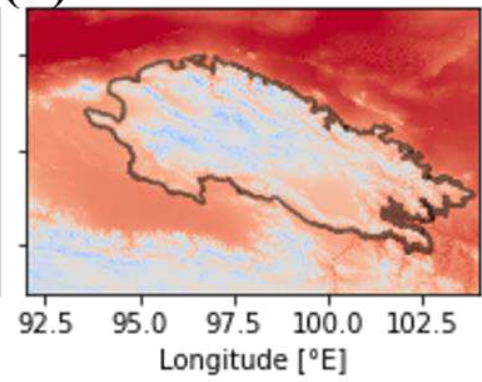

(a-d) based on method 4 (2071-2100)
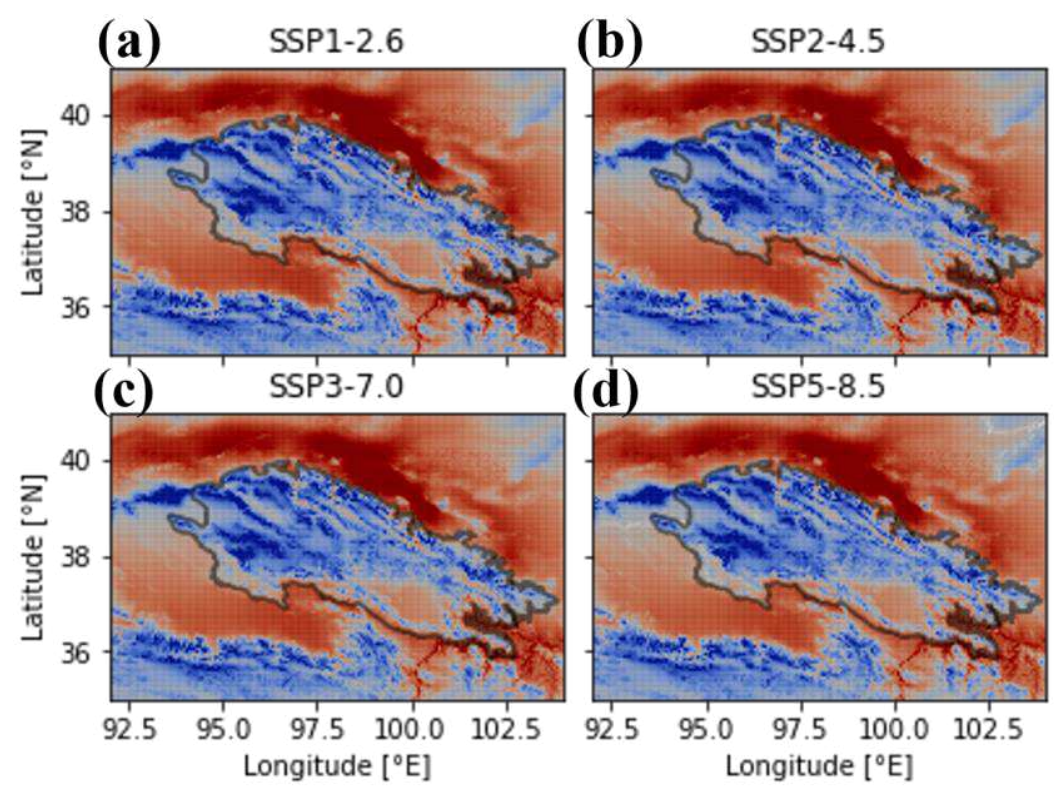

(d)

SSP5-8.5

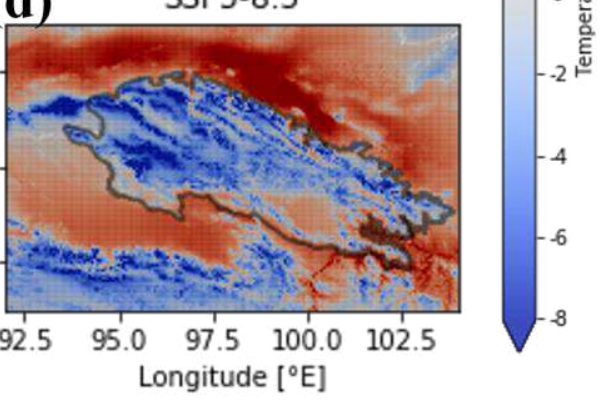


Figure 8 Temperature differences for the four emission scenarios (a-d) for method 4 and method 1 (2071-2100). Statistically significant differences are indicated by black dots.

(a)

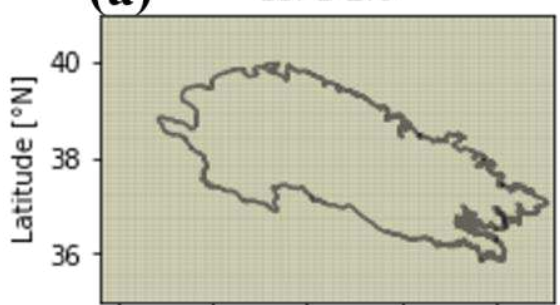

(c)

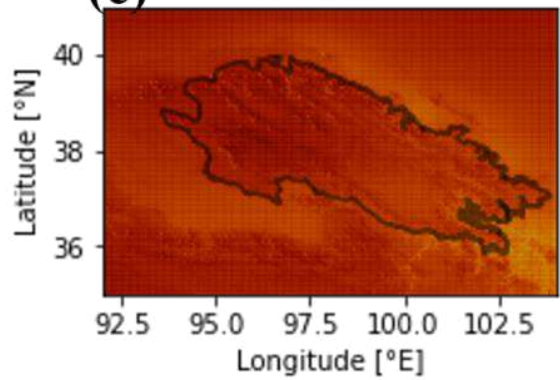

(b) SSP2-4.5

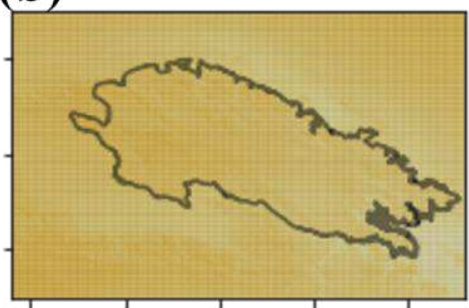

(d)

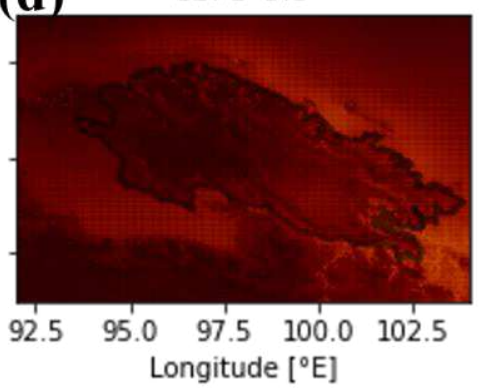

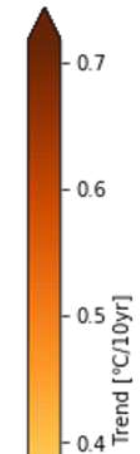

$-0.3$

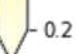

Figure 9 Temperature trends from method 4 for the four emission scenarios $(a-d)$ in the future period (2015-2100). Statistically significant trends are indicated by black dots.
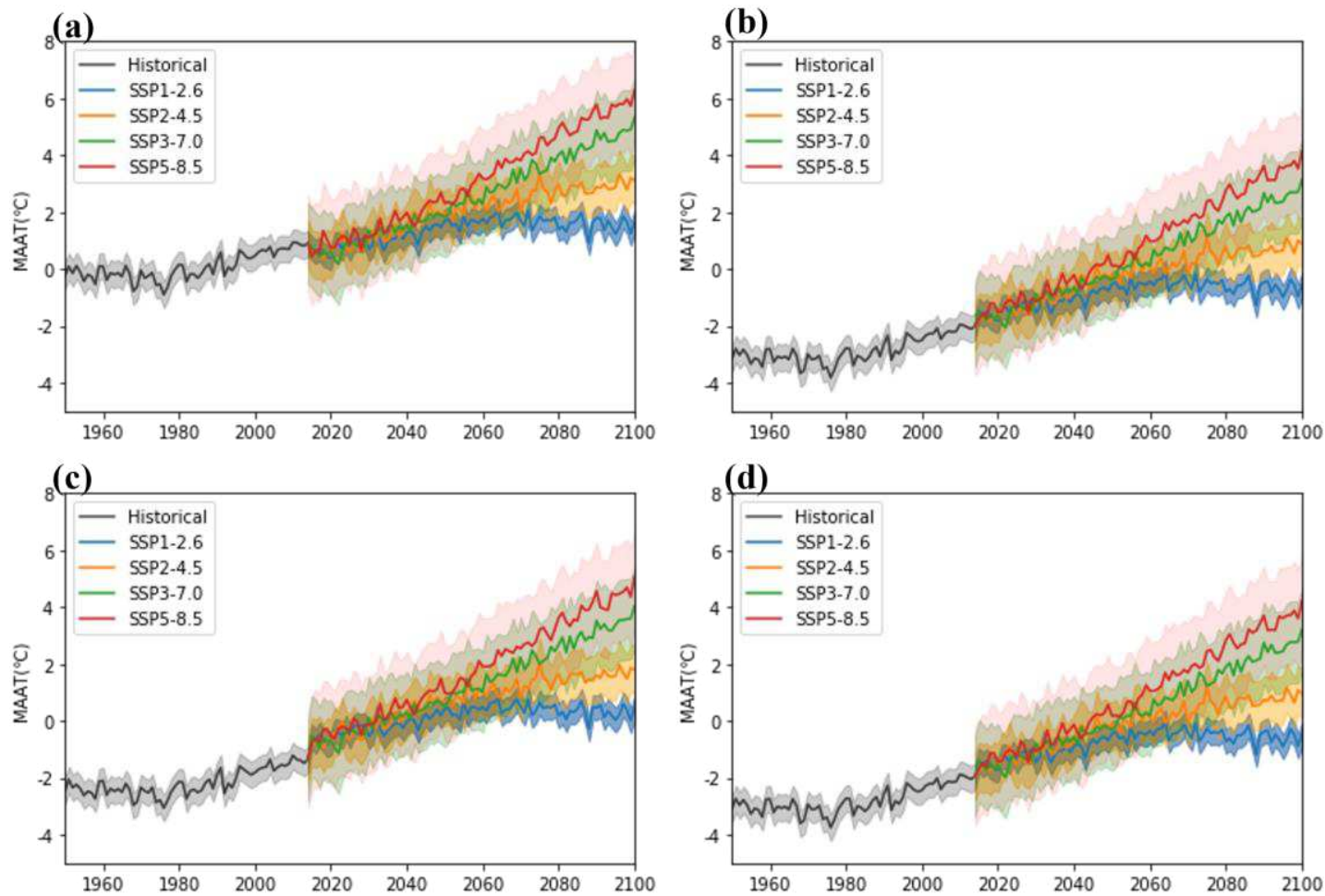

Figure 10 Average annual temperatures in the Qilian Mountains for the four future scenarios based on methods $1-4(\mathrm{a}-\mathrm{d})$. 


\section{Discussion}

\subsection{Differences in downscaling results}

There are a number of sources for errors and uncertainty in this study. Elevation has been shown to be an important error source, especially in high mountains (L Gao et al., 2012; Lu Gao, Hao, et al., 2014). Calculating near-surface air temperature based on sparse station observations or via interpolation using climate model output with limited spatial resolution are also common approaches (Dodson \& Marks, 1997; Ishida \& Kawashima, 1993; Vicente-Serrano et al., 2003). However, these approaches always fail in regions with complex terrain where temperature changes across short distances, if the relationship between temperature and elevation is ignored. Therefore, applying method 2 based on elevation can be useful for reducing this type of error. Indeed, our results indicate that by using method 2, annual RMSE and MAE can be reduced by $61.62 \%$ and $64.10 \%$, respectively.

With an increase in elevation, the regional atmospheric circulation is increasingly affected by the large-scale circulation, which also implies that the near surface air temperature becomes dominated by the upper-air temperature (Tabony, 1985). Method 3, based on data at corresponding pressure levels, accounts for the influence of circulation and annual RMSE and MAE are reduced by $59.24 \%$ and $61.58 \%$. Method 2, although it is also greatly improved compared to the original data, indicates somewhat less improvement. This is likely due to the heterogeneous surface effects in mountainous areas (Cao et al., 2017). A valley, with only a small area surrounded by mountains, will be subject to surface effects much more so than a mountain peak. Based on this situation, the hypsometric position - values ranging from 1 (lowest point in a valley) to 0 (highest peak) —was considered as part of method 4 , combining methods 2 and 3. As expected, method 4 illustrates the best performance with annual RMSE and MAE reduced by $63.48 \%$ and $65.96 \%$.

The verification results of methods 2 and method 4 are very similar, likely because, out of the 22 meteorological stations, only one station's hypsometric position indicated that it is not primarily controlled by surface temperature. Based on the station that is not primarily influenced by surface effects, method 4 shows a greater 
reduction in RMSE and MAE than method 2 based on only surface or upper-level temperatures. It could be argued that the hypsometric position is an effective method to reduce errors caused by complex terrain in mountainous areas. Thus, using more stations with different hypsometric positions would help to further verify the method.

\subsection{Shortcomings and future research}

The verification indicates that although errors are reduced substantially by these downscaling methods, errors in winter are generally higher than in summer. This could be due to temperature inversions during winter, when the surface temperature is lower than the upper-level temperatures in mountainous areas (Lareau et al., 2013). Winter inversions are caused by the accumulation of colder air in valleys due to cold air drainage (Kiefer \& Zhong, 2015; Mahrt et al., 2001).

Method 4, despite applying a hypsometric position to distinguish valleys and peaks, is potentially still limited due to strong inversions that occur in winter, but are absent in the warm season. Therefore, the control of the near-surface air temperature varies seasonally, rather than being uniform throughout the year. To alleviate this problem, winter inversions could be simulated based on surface net radiation or the Richardson number using CMIP6 data (Grachev, Andreas, Fairall, Guest, \& Persson, 2013; K. Wang \& Liang, 2008). Establishing more stations in basins and valleys could also be useful to further account for hypsometric position.

By applying the above methods, some of the problems due to different variables, e.g., elevation and hypsometric position, have been reduced in downscaling nearsurface air temperature. These methods may also be useful in reducing shortcomings due to other environment conditions (e.g., snow, precipitation, and soil temperature) (Lin, Wei, Yang, Zhang, \& Zhang, 2016; Liston \& Elder, 2006).

\section{Conclusions}

Air temperature is one of the most important variables for assessing global climate. High-resolution temperatures are crucial for quantifying climate change, especially in complex terrain. Therefore, three statistical downscaling methods (method 2-4) have been used in the Qilian Mountains and compared with the original 
data that were bilinearly interpolated (method 1). Errors are greatly reduced via these methods: the annual RMSE and MAE are lower by $61.62 \%$ and $64.10 \%$ based on downscaling method 2, by $59.24 \%$ and $61.58 \%$ based on method 3, and by $63.48 \%$ and $65.96 \%$ based on method 4 .

Using the results derived from the best-performing method 4, downscaled temperature data are substantially lower in high-elevation regions area compared to the original temperature data. The average differences are $-2.85 \pm 3.61^{\circ} \mathrm{C}$ during $1981-2010$ in the historical period, and $-2.13 \pm 3.30^{\circ} \mathrm{C}$ for SSP1-2.6, $-2.13 \pm 3.29^{\circ} \mathrm{C}$ for SSP2-4.5, $-2.11 \pm 3.24^{\circ} \mathrm{C}$ for SSP3-7.0, and $-2.12 \pm 3.23^{\circ} \mathrm{C}$ for SSP5-8.5 during the 2071-2100 future periods.

The warming trends based on method 4 for the area-averaged mean annual air temperature are $0.183 \pm 0.016^{\circ} \mathrm{C} / 10 \mathrm{yr}$ for the historical 1950-2014 period, and $0.117 \pm 0.011^{\circ} \mathrm{C} / 10 \mathrm{yr}$ for $\mathrm{SSP} 1-2.6, \quad 0.315 \pm 0.017^{\circ} \mathrm{C} / 10 \mathrm{yr}$ for SSP2-4.5, $0.563 \pm 0.031^{\circ} \mathrm{C} / 10 \mathrm{yr}$ for SSP3-7.0, and $0.677 \pm 0.036^{\circ} \mathrm{C} / 10 \mathrm{yr}$ for SSP5-8.5 during 2015-2100.

Although the accuracy of the temperature data has been greatly improved by the downscaling methods, further improvement is still possible, especially in winter. Applying these methods to different gridded products (e.g., ERA5, NCEP-2, JRA-55) and including additional driving factors that can affect the downscaling performance would be a useful direction for future research.

\section{Appendix}




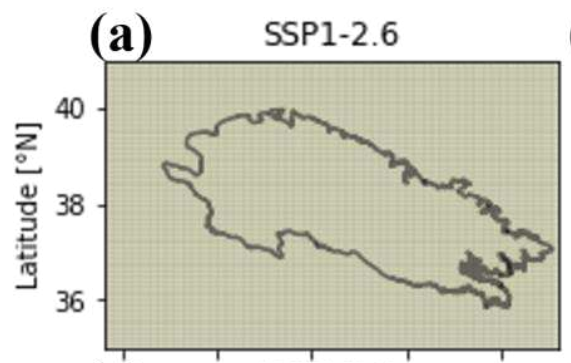

(c)

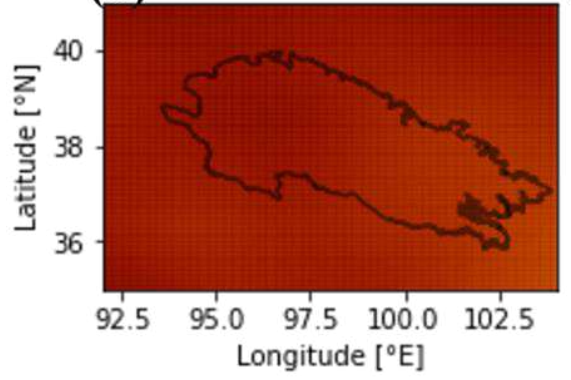

(b) SSP $2-4.5$

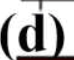

(d)

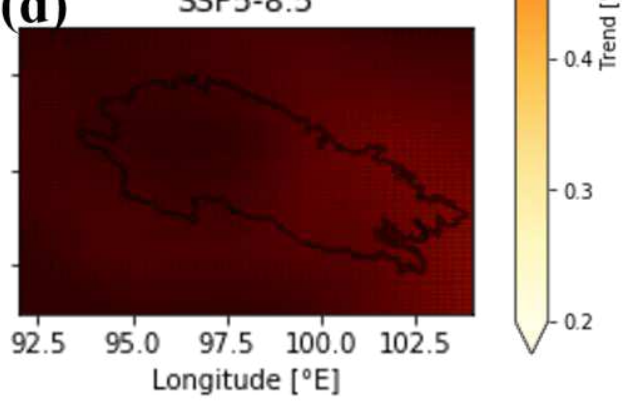

356

Figure S1 Temperature trends from method 1 for the four emission scenarios $(\mathrm{a}-\mathrm{d})$ in the future period (2015-2100). Statistically significant trends are indicated by black dots

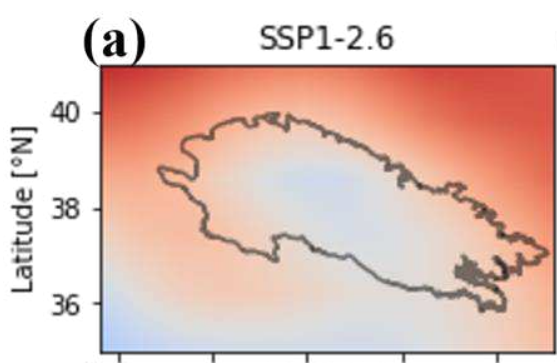

(b)
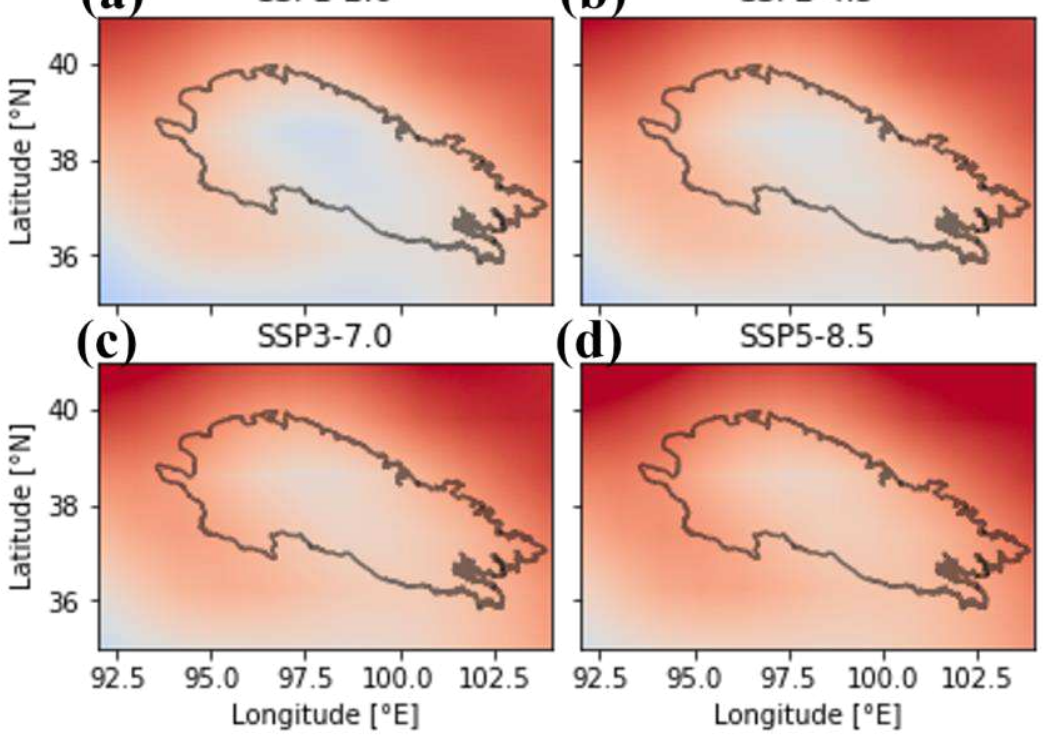

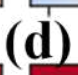

SSP5-8.5

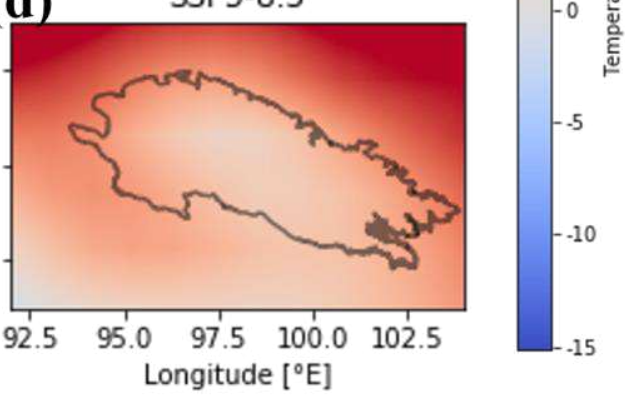

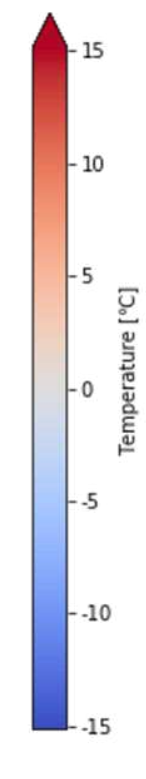

Figure S2 The spatial pattern of annual air temperatures for the four emission scenarios (a-d) based on method 1 (2071-2100) 

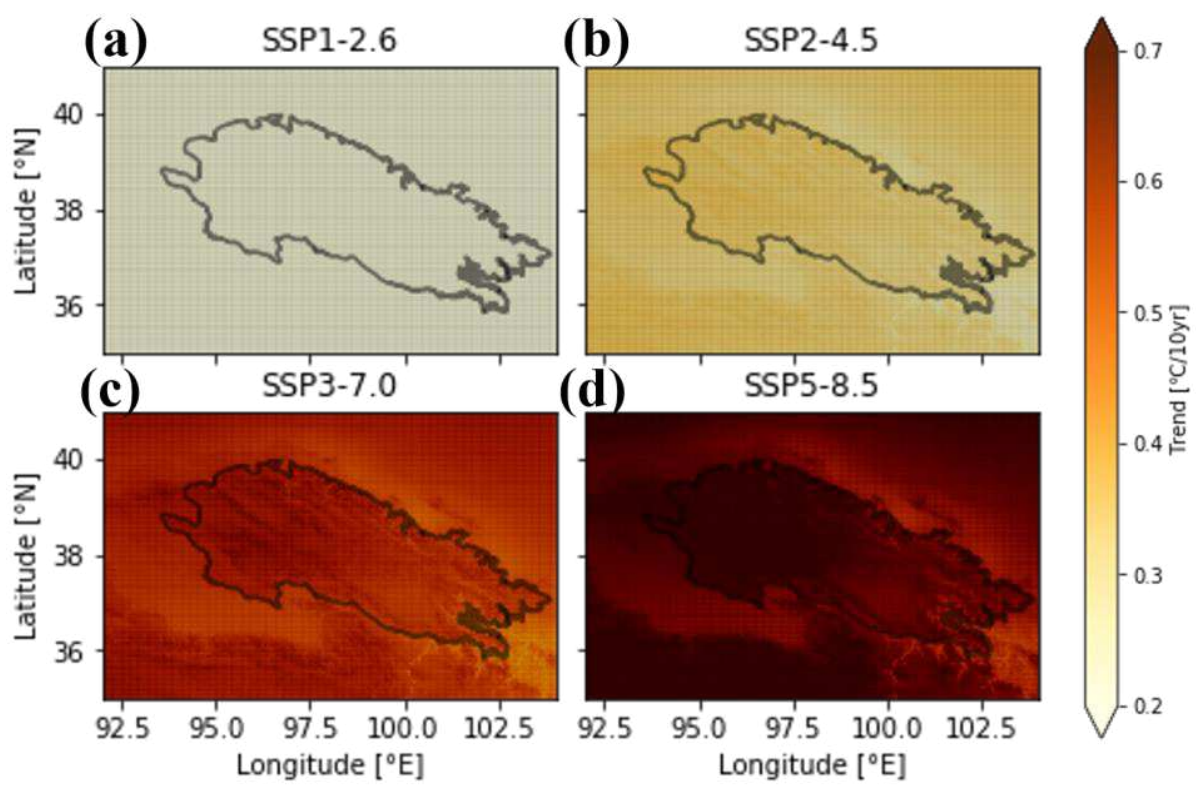

Figure $\mathbf{S 3}$ Temperature trends from method 2 for the four emission scenarios $(\mathrm{a}-\mathrm{d})$ in the future period (2015-2100). Statistically significant trends are indicated by black dots
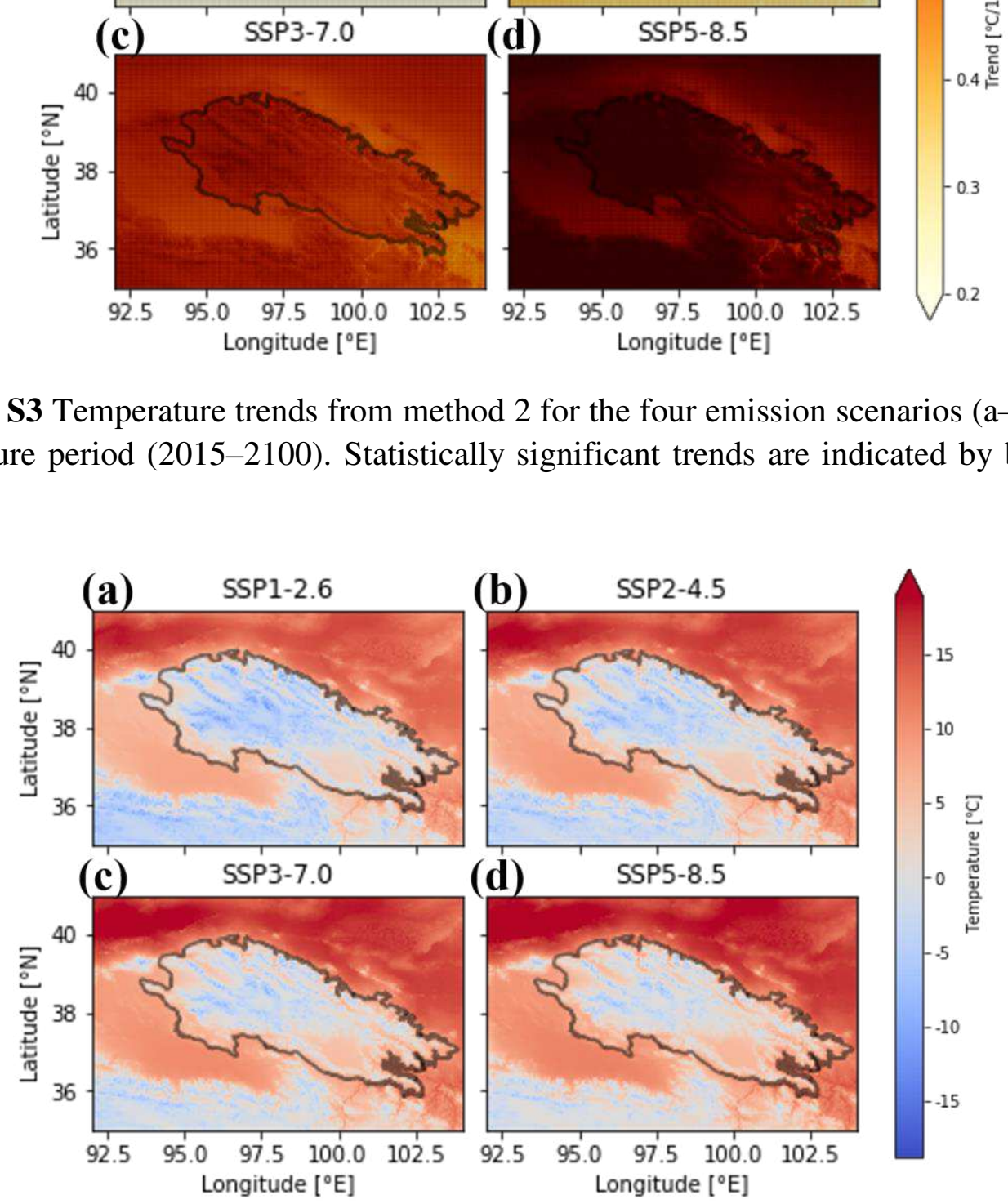

Figure S4 The spatial pattern of annual air temperatures for the four emission scenarios (a-d) based on method 2 (2071-2100) 

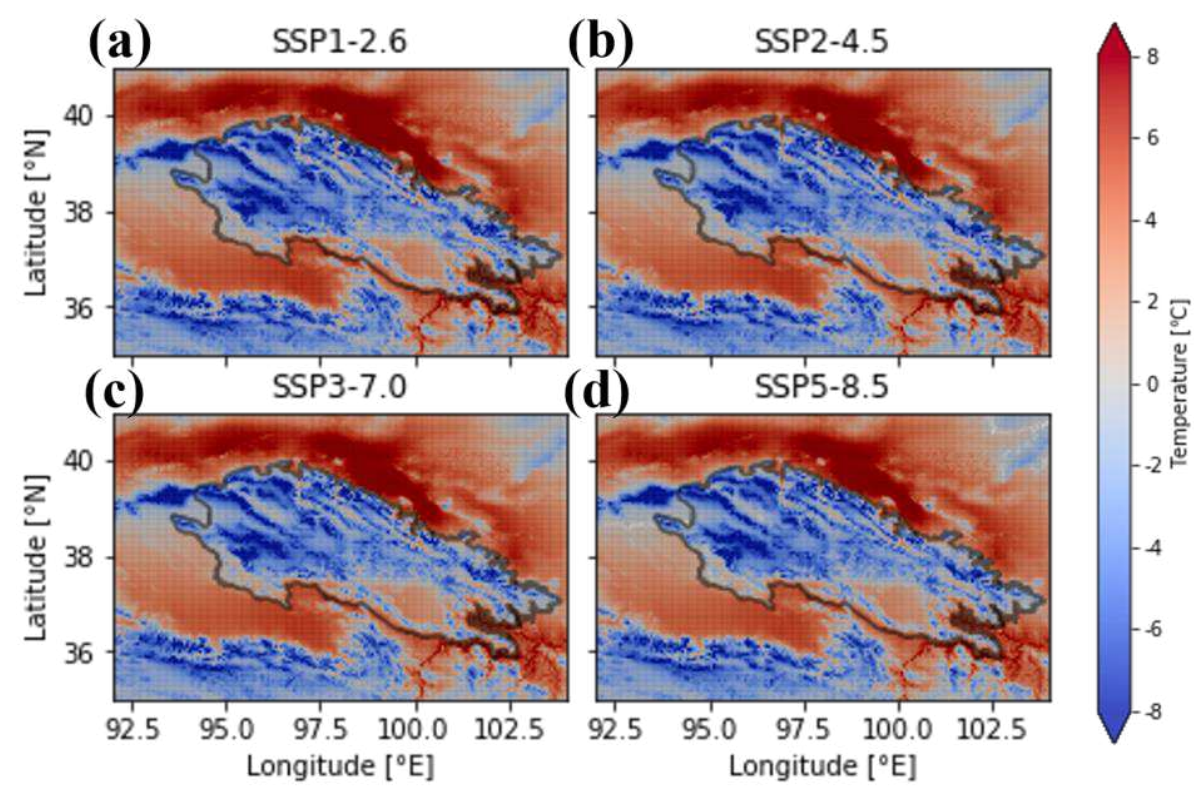

Figure S5 Temperature differences for the four emission scenarios (a-d) for method 2 and method 1 (2071-2100). Statistically significant differences are indicated by black dots.
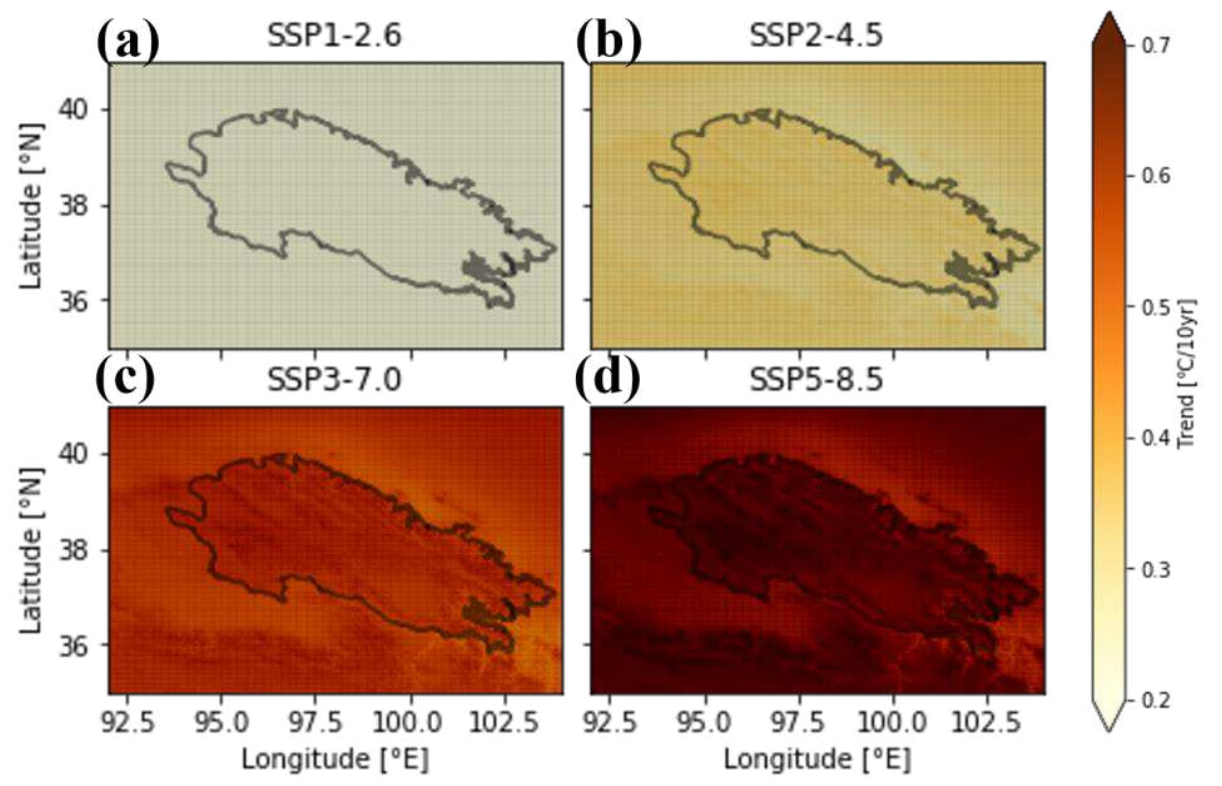

Figure S6 Temperature trends from method 3 for the four emission scenarios $(a-d)$ in the future period (2015-2100). Statistically significant trends are indicated by black dots 

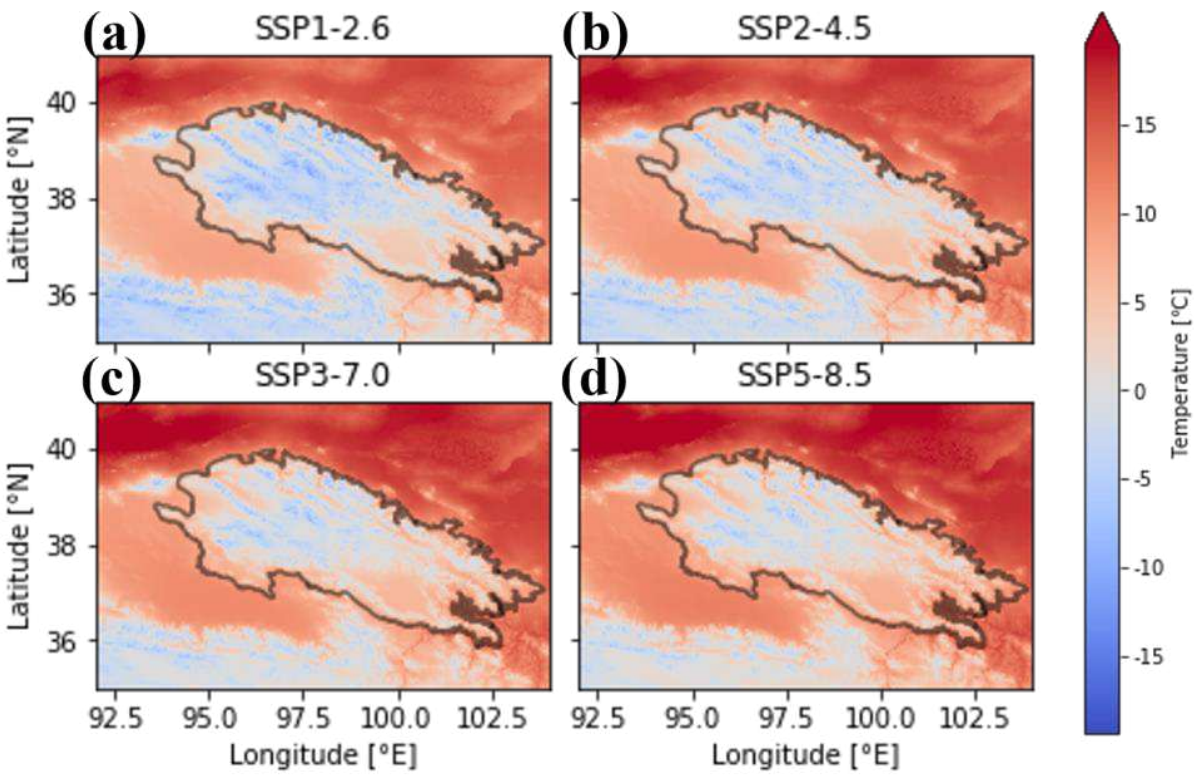

Figure S7 The spatial pattern of annual air temperatures for the four emission scenarios (a-d) based on method 3 (2071-2100)
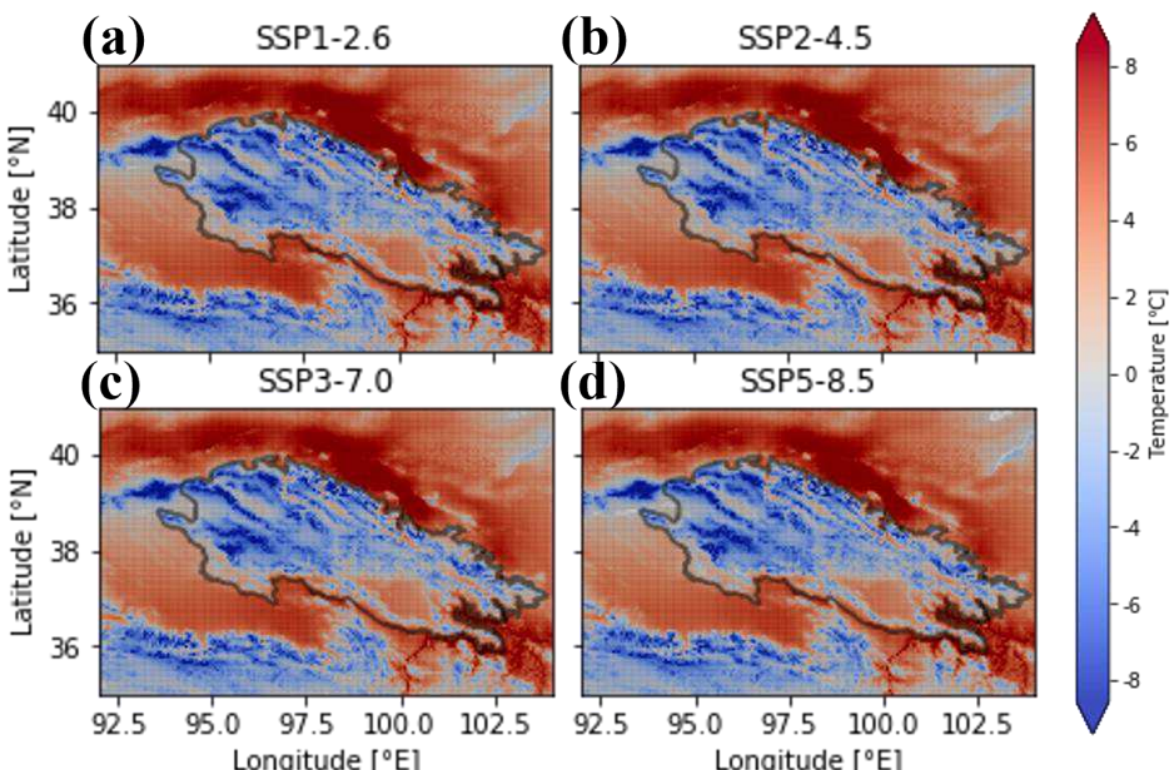

(c)

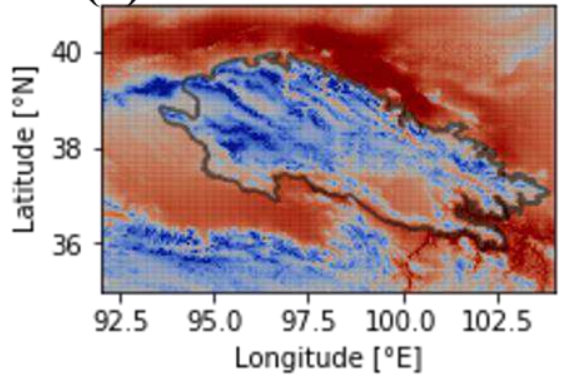

(d)

SSP5-8.5

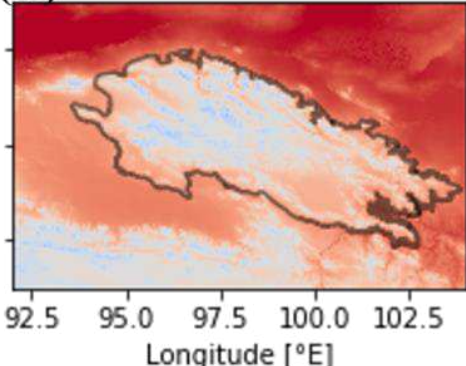

SSP5-8.5

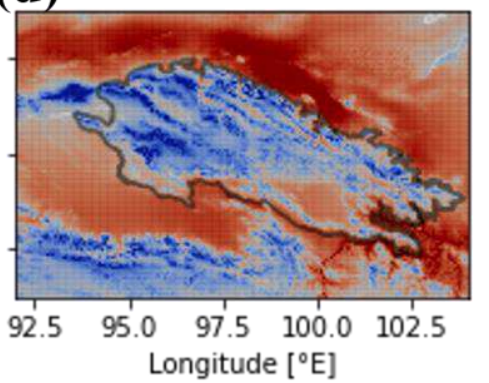

\section{.}

382 Figure S8 Temperature differences for the four emission scenarios (a-d) for method 3 383 and method 1 (2071-2100). Statistically significant differences are indicated by black 384 dots.

\section{Funding}

This study was supported the National Key R\&D Program of China (2019YFC0507403), the National Natural Science Foundation of China (grant No. 42171120, 42161160328, 42101134), the Fundamental Research Funds for the 


\section{Authorship contribution}

Haodong Jin: Methodology, Writing - original draft, Validation, Writing -review \& editing;Xiaodong Li: Writing - review \& editing;Oliver W. Frauenfeld: Writing review \& editing; Yaohua Zhao: Resources;Cong Chen: Resources;Ran Du: Resources;Jun Du: Writing - review \& editing;Xiaoqing Peng: Writing - review \& editing, Funding acquisition.

\section{Availability of data and material}

Available on request.

\section{Code availability}

Not applicable.

\section{Declarations}

\section{Competing interests}

The authors declare no competing interests.

\section{Ethics approval}

We confrm that this article is an original research and has not been published or presented previously in any journal or conference in any language.

\section{Consent to participate}

All the authors consent to participate in this process.

\section{Consent for publication}

Authors agree to publish this paper.

\section{Reference}

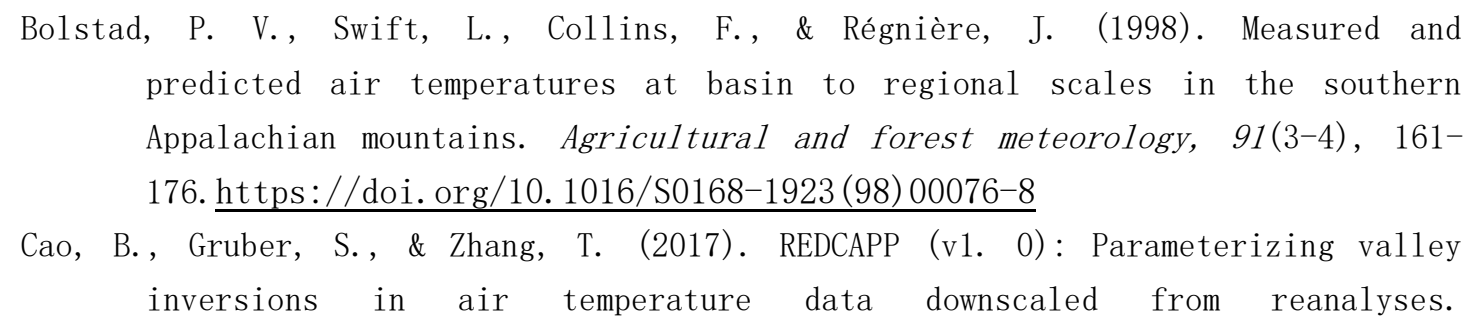


Geoscientific Model Development, 10(8),

2923. https://doi. org/10.5194/gmd-10-2905-2017

Cao, B., Zhang, T., Wu, Q., Sheng, Y., Zhao, L., \& Zou, D. (2019). Permafrost zonation index map and statistics over the Qinghai-Tibet Plateau based on field evidence. Permafrost and Periglacial Processes, 30(3), 178194. https://doi.org/10. 1002/ppp. 2006

Chu, J., Xia, J., Xu, C. -Y., \& Singh, V. (2010). Statistical downscaling of daily mean temperature, pan evaporation and precipitation for climate change scenarios in Haihe River, China. Theoretical and Applied Climatology, 99(1), 149-161. https://doi. org/10. 1007/s00704-009-0129-6

Collins, W. J., Lamarque, J.-F., Schulz, M., Boucher, 0., Eyring, V., Hegglin, M. I. . . . Shindell, D. (2017). AerChemMIP: quantifying the effects of chemistry and aerosols in CMIP6. Geoscientific Model Development, 10(2), 585-607. https://doi. org/10. 5194/gmd-10-585-2017

Coppola, E., \& Giorgi, F. (2010). An assessment of temperature and precipitation change projections over Italy from recent global and regional climate model simulations. International Journal of Climatology: A Journal of the Royal Meteorological Society, 30(1), 11-32. https://doi.org/10.1002/joc. 1867

Dodson, R., \& Marks, D. (1997). Daily air temperature interpolated at high spatial resolution over a large mountainous region. Climate research, 8(1), 120. https://doi.org/10.3354/cr008001

Eyring, V., Bony, S., Meeh1, G. A., Senior, C. A., Stevens, B., Stouffer, R. J., \& Taylor, K. E. (2016). Overview of the Coupled Model Intercomparison Project Phase 6 (CMIP6) experimental design and organization. Geoscientific Model Development, 9(5), 1937-1958. https://doi.org/10.5194/gmd-9-1937-2016

Fiddes, J., \& Gruber, S. (2014). TopoSCALE v. 1.0: downscaling gridded climate data in complex terrain. Geoscientific Model Development, 7(1), 387405. https://doi.org/10.5194/gmd-7-387-2014

Gao, L., Bernhardt, M., \& Schulz, K. (2012). Downscaling ERA-Interim temperature data in complex terrain. Hydrology \& Earth System Sciences Discussions, 9(5). https://doi.org/10. 5194/hessd-9-5931-2012

Gao, L., Hao, L., \& Chen, X. ${ }^{-w}$. (2014). Evaluation of ERA-interim monthly temperature data over the Tibetan Plateau. Journal of Mountain Science, 11(5), 1154-1168. https://doi. org/10. 1007/s11629-014-3013-5

Gao, L., Schulz, K., \& Bernhardt, M. (2014). Statistical downscaling of ERA-interim forecast precipitation data in complex terrain using lasso algorithm. Advances in Meteorology, 2014. https://doi.org/10.1155/2014/472741

Gao, L., Wei, J., Wang, L., Bernhardt, M., Schulz, K., \& Chen, X. (2018). A highresolution air temperature data set for the Chinese Tian Shan in $1979-2016$. Earth System Science Data, 10(4), 2097-2114. https://doi.org/10.5194/essd10-2097-2018

Gao, X., Shi, Y., \& Giorgi, F. (2011). A high resolution simulation of climate change over China. Science China Earth Sciences, 54(3), 462472. https://doi. org/10. 1007/s11430-010-4035-7 
Grachev, A. A., Andreas, E. L., Fairal1, C. W., Guest, P. S., \& Persson, P. 0. G. (2013). The critical Richardson number and limits of applicability of local similarity theory in the stable boundary layer. Boundary-layer meteorology, 147(1), 51-82. https://doi.org/10. 1007/s10546-012-9771-0

Hagemann, S., Machenhauer, B., Jones, R., Christensen, 0., Déqué, M., Jacob, D., \& Vidale, P. L. (2004). Evaluation of water and energy budgets in regional climate models applied over Europe. Climate Dynamics, 23(5), 547567. https://doi.org/10. 1007/s00382-004-0444-7

Hay, L. E., \& Clark, M. (2003). Use of statistically and dynamically downscaled atmospheric model output for hydrologic simulations in three mountainous basins in the western United States. Journal of Hydrology, 282(1-4), 5675. https://doi. org/10. 1016/S0022-1694(03) 00252-X

Ishida, T., \& Kawashima, S. (1993). Use of cokriging to estimate surface air temperature from elevation. Theoretical and Applied Climatology, 47(3), 147-157. https://doi. org/10.1007/BF00867447

Kiefer, M. T., \& Zhong, S. (2015). The role of forest cover and valley geometry in cold - air pool evolution. Journal of Geophysical Research: Atmospheres, 120(17), 8693-8711. https://doi.org/10. 1002/2014JD022998

Kunkel, K. E. (1989). Simple procedures for extrapolation of humidity variables in the mountainous western United States. Journal of Climate, 2(7), 656669. https://doi. org/10. 1175/1520-0442(1989) 002<0656:SPFEOH $>2$. 0. C0;2

Lareau, N. P., Crosman, E., Whiteman, C. D., Hore1, J. D., Hoch, S. W., Brown, W. 0. , \& Horst, T. W. (2013). The persistent cold-air pool study. Bulletin of the American Meteorological Society, 94(1), 5163. https://doi. org/10. 1175/BAMS-D-11-00255. 1

Li, B., Sun, Y., Guo, W., Shan, X., Wang, P., Pang, S., . . . Zhang, G. (2017). The mechanism and verification analysis of permafrost-associated gas hydrate formation in the Qilian Mountain, Northwest China. Marine and Petroleum Geology, 86, 787-797. https://doi.org/10. 1016/j.marpetgeo.2017.05. 036

Lin, P., Wei, J., Yang, Z. L., Zhang, Y., \& Zhang, K. (2016). Snow data assimilation - constrained land initialization improves seasonal temperature prediction. Geophysical Research Letters, 43(21), 11,423411, 432. https://doi. org/10. 1002/2016GL070966

Liston, G. E., \& Elder, K. (2006). A distributed snow-evolution modeling system (SnowMode1). Journal of Hydrometeorology, $\quad 7(6), \quad$ 12591276. https://doi. org/10. 1175/JHM548. 1

Mahrt, L., Vickers, D., Nakamura, R., Soler, M., Sun, J., Burns, S., \& Lenschow, D. (2001). Shallow drainage flows. Boundary-layer meteorology, 101(2), 243260. https://doi. org/10. 1023/A: 1019273314378

Mao, K., Tang, H., Wang, X., Zhou, Q., \& Wang, D. (2008). Near - surface air temperature estimation from ASTER data based on neural network algorithm. International Journal of Remote Sensing, 29(20), 60216028. https://doi. org/10. 1080/01431160802192160

Maraun, D., Wetterhal1, F., Ireson, A., Chandler, R., Kendon, E., Widmann, M., . . . 
Themeß1, M. (2010). Precipitation downscaling under climate change: Recent developments to bridge the gap between dynamical models and the end user. Reviews of geophysics, 48(3). https://doi.org/10.1029/2009RG000314

Maurer, E. P., Wood, A. W., Adam, J. C., Lettenmaier, D. P., \& Ni jssen, B. (2002). A long-term hydrologically based dataset of land surface fluxes and states for the conterminous United States. Journal of Climate, 15(22), 32373251. https://doi. org/10. 1175/1520-0442 (2002) 015<3237:ALTHBD $>2.0$. C0;2

Minder, J. R., Mote, P. W., \& Lundquist, J. D. (2010). Surface temperature lapse rates over complex terrain: Lessons from the Cascade Mountains. Journal of Geophysical Research: Atmospheres, 115(D14). https://doi. org/10. 1029/2009JD013493

Mooney, P. A., Mulligan, F. J., \& Fealy, R. (2011). Comparison of ERA - 40, ERA Interim and NCEP/NCAR reanalysis data with observed surface air temperatures over Ireland. International Journal of Climatology, 31(4), 545-557. https://doi. org/10. 1002/joc. 2098

Mote, P. W. (2006). Climate-driven variability and trends in mountain snowpack in western North America. Journal of Climate, 19(23), 62096220. https://doi. org/10. 1175/JCLI3971. 1

Prihodko, L., \& Goward, S. N. (1997). Estimation of air temperature from remotely sensed surface observations. Remote Sensing of Environment, 60(3), 335346. https://doi. org/10. 1016/S0034-4257 (96)00216-7

Prince, S., Goetz, S., Dubayah, R., Czajkowski, K., \& Thawley, M. (1998). Inference of surface and air temperature, atmospheric precipitable water and vapor pressure deficit using Advanced Very High-Resolution Radiometer satellite observations: comparison with field observations. Journal of Hydrology, 212, 230-249. https://doi. org/10. 1016/S0022-1694(98)00210-8

Rolland, C. (2003). Spatial and seasonal variations of air temperature lapse rates in Alpine regions. Journal of Climate, 16(7), 10321046. https://doi. org/10. 1175/1520-0442(2003)016<1032:SASV0A $>2.0$. C0;2

Rong, Y., Su, H., Zhang, R., Tian, J., Chen, S., Yang, Y., \& Li, B. (2011). A new physically based method for air temperature downscaling. Paper presented at the 2011 IEEE International Geoscience and Remote Sensing Symposium. https://doi. org/10. 1109/IGARSS. 2011. 6049474

Souvignet, M., Gaese, H., Ribbe, L., Kretschmer, N., \& Oyarzun, R. (2010). Statistical downscaling of precipitation and temperature in north - central Chile: an assessment of possible climate change impacts in an arid Andean watershed. Hydrological Sciences Journal - Journal des Sciences Hydrologiques, 55(1), 41-57.https://doi.org/10.1080/02626660903526045

Tabony, R. (1985). Relations between minimum temperature and topography in Great Britain. Journal of Climatology, 503520. https://doi. org/10. 1002/ joc. 3370050504

Vicente-Serrano, S. M., Saz-Sánchez, M. A., \& Cuadrat, J. M. (2003). Comparative analysis of interpolation methods in the middle Ebro Valley (Spain): application to annual precipitation and temperature. Climate research, 
24(2), 161-180. https://doi.org/10.3354/cr024161

Wang, K., \& Liang, S. (2008). An improved method for estimating global evapotranspiration based on satellite determination of surface net radiation, vegetation index, temperature, and soil moisture. Journal of Hydrometeorology, 9(4), 712-727. https://doi.org/10. 1175/2007JHM911.1

Wang, X., Vandenberghe, D., Yi, S., Vandenberghe, J., Lu, H., Van Balen, R., \& Van den Haute, P. (2013). Late Quaternary paleoclimatic and geomorphological evolution at the interface between the Menyuan basin and the Qilian Mountains, northeastern Tibetan Plateau. Quaternary Research, 80(3), 534544. https://doi. org/10.1016/j. yqres. 2013.08.004

Yang, T., Li, H., Wang, W., Xu, C. Y., \& Yu, Z. (2012). Statistical downscaling of extreme daily precipitation, evaporation, and temperature and construction of future scenarios. Hydrological Processes, 26(23), 35103523. https://doi. org/10.1002/hyp. 8427 